\title{
Of gold masks, bronze mirrors and brass bracelets: Analyses of metallic artefacts from Samdzong, Upper Mustang, Nepal 450-650 CE
}

\author{
Giovanni Massa, Mark Aldenderfer and Marcos Martinón-Torres \\ https://doi.org/10.1016/j.ara.2019.02.004
}

Paper published in Archaeological Research in Asia, 2019

\begin{abstract}
The site of Samdzong is composed of a series of shaft tombs situated at $4000 \mathrm{~m}$ altitude in the Himalayas. Recent archaeological expeditions have recovered an exceptional metal assemblage including gold and silver masks, copper vessels, iron daggers, brass bangles and a bronze medallion. The richness and variety of the collection provided an unusual starting point to investigate trade and regional exchange patterns in the period 450-650 CE, in combination with data from other materials. Here we present a stylistic, metallographic, elemental and isotopic study of a selection of the metal objects. The results suggest a South Asian origin for the bulk of the metals, while evidencing a variety of technological and cultural traditions that show connections with Central Asia and the Silk Road. This is one of the first comprehensive analyses of archaeological metal objects from the High Himalayas, offering a baseline for future comparative studies.
\end{abstract}

Keywords

Archaeometallurgy; Gold; Silver; Copper; Lead isotope analysis; Himalayas; Silk Road

\section{Introduction}

Although Nepal has a long history of metalworking that reaches back at least 1600 years and is known principally from workshops in the Kathmandu Valley (Slusser and Vajracharya, 1975), most of the research on it has focused upon the rituals involved in the mining and smelting of copper or the creation of copper, brass, and bronze statuary used in Hindu and Buddhist ritual (Anfinset, 2000; Furger, 2017). However, very little research has been done on more quotidian metal artefacts, such as weapons, cooking, drinking and storage vessels, and simple jewelry, or artefacts associated with mortuary activity. In great part, this stems from a dearth of excavations in Nepal at residential and mortuary sites, and it is especially true of the prehistoric and early historic periods.

In 2010, the site of Samdzong, located in the far northern reaches of the Kali Gandaki valley in Upper Mustang near the southern border of the Tibet Autonomous Region, was discovered and subsequently excavated from 2011 to 2013 (Fig. 1). A wealth of metal objects was recovered, spanning a range of compositions, typologies and styles. In this manuscript, we offer an assessment of the chemical composition and manufacturing processes of a selection of them. This represents the first comprehensive analysis of metals in Nepal for the period 450-650 CE and one of the first studies of quotidian and mortuary metal objects anywhere in the High Himalayas. Not only does this analysis 
provide a baseline for future comparative studies of Nepali metalworking, it also offers insights into trade and regional exchange patterns during this era.

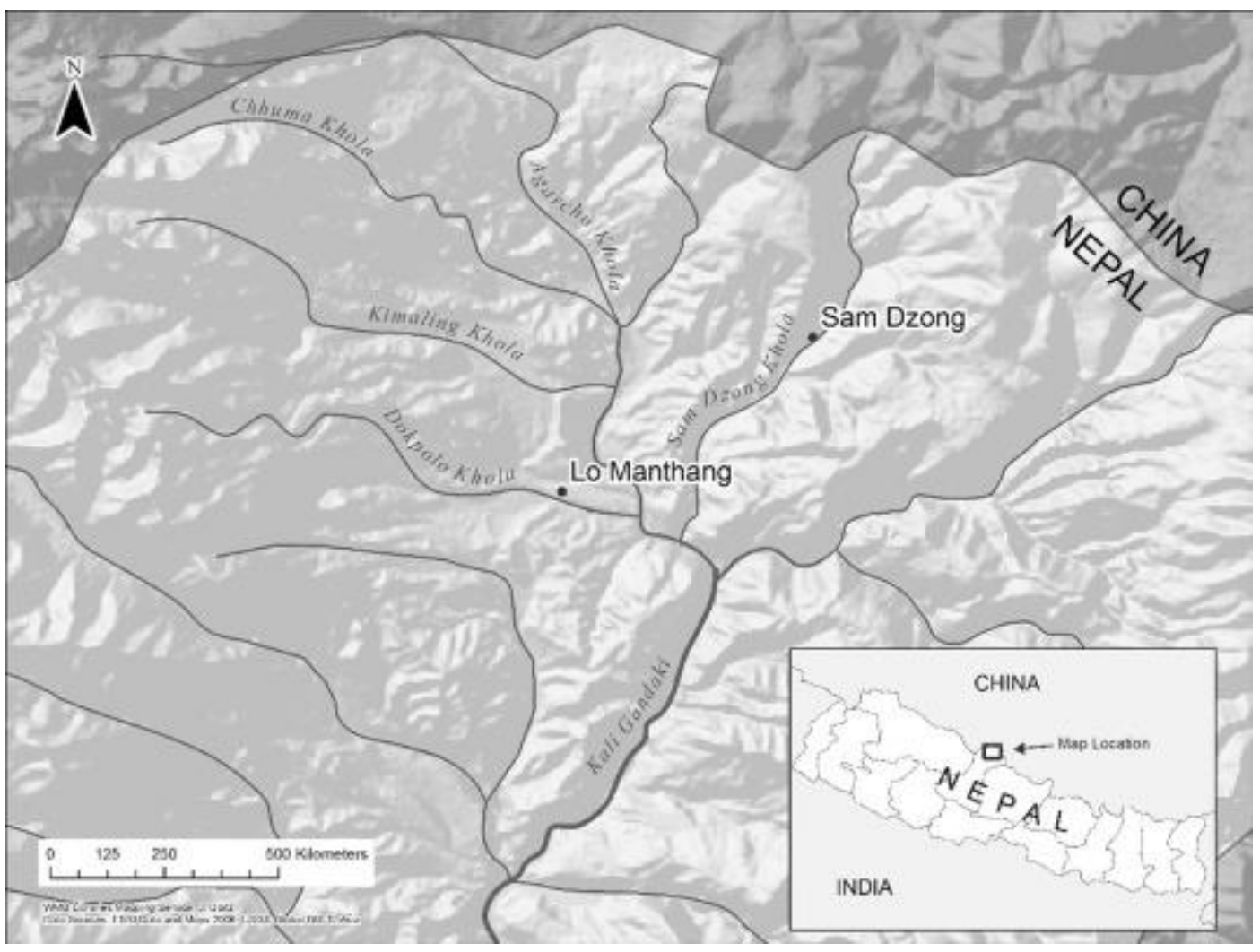

Fig. 1. Map of the Kali Gandaki valley with the village of Samdzong. (J-Glatz).

\subsection{The archaeological context at Samdzong}

Samdzong is located at an elevation of $4000 \mathrm{~m}$ above mean sea level on the east side of the Samdzong Khola, a small stream that drains into the Kali Gandaki River, and approximately $1 \mathrm{Km}$ south of the modern, but now abandoned, village of Samdzong.

The site is found along the sheer face of a west-facing bluff that has a vertical elevation of $30 \mathrm{~m}$. In 2009, a seismic event shattered the cliff face and exposed ten shaft tombs and their chambers; prior to this, the local villagers were unaware of their presence. This event unfortunately collapsed the ceilings of many of the tombs, thus disturbing their context and mixing their deposits, and some of their contents were spilled to the base of the cliff.

The complex consists of ten shaft tombs stretched out along the cliff face, and which are found in three distinct groups across the face of the cliff: Samdzong 3 is at the north end of the cliff; nine meters to the south is a tightly clustered central group composed of Samdzong 1, 4, 5, 6, 7, 8; Samdzong 2, 9, and 10 are found six meters south of this group (Fig. 2). Although the total number of shafts is not known, Samdzong 3, 2, 9, and 10 each had their own shafts. The central group may have been served by one or possibly, two shafts. It is likely that the opening of the shaft along the ridgeline would have been visible to anyone walking along it since it is likely that the tombs, which appear to have been used for consecutive multiple burials, had stone caps that served to close the opening. Remnants of these stone caps can be seen above Samdzong 3. Today, the chambers can only be accessed with climbing gear (Aldenderfer and Eng, 2016). 


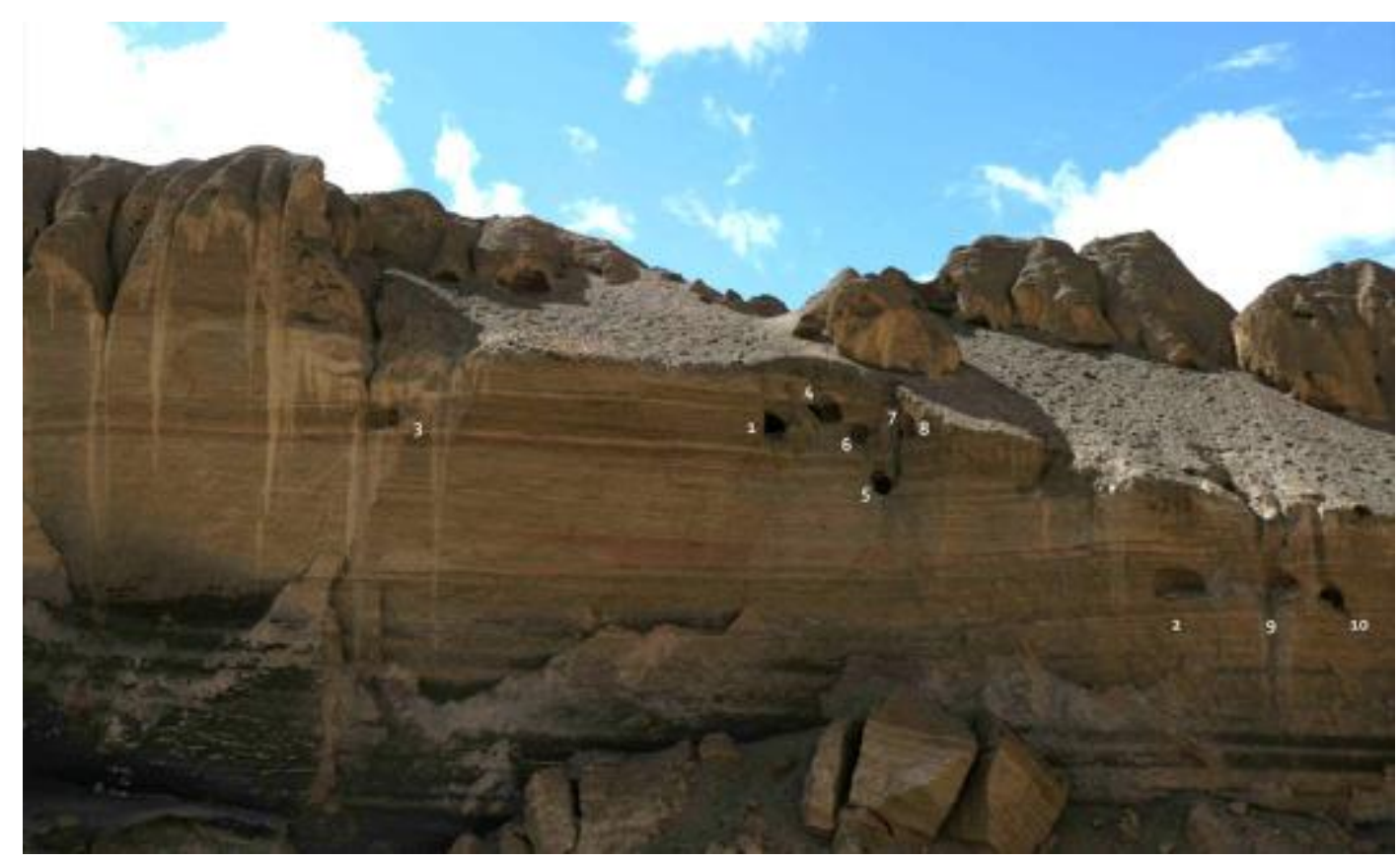

Fig. 2. The chambers of shaft tombs exposed at Samdzong (Photo: M. Aldenderfer).

The Samdzong tombs served as a community mortuary facility, although the numbers of individuals found within each tomb context varied. Samdzong 5, where most of the artefacts described below were found, contained two individuals: an adult of indeterminate sex, and the very fragmentary remains of a juvenile, aged 8-12. In contrast, Samdzong 1-4, which consisted of four separate but linked chambers, contained 83 individuals. Males and females were found in the Samdzong tombs: infants (ages $0-2 ; 8.6 \%$ of the total assemblage), children (ages $3-7 ; 11.4 \%$ ), juveniles (ages 8-12; 9.5\%), adolescents (ages 13-19; 6.7\%); young adults (ages 20-34; 8.6\%), middle aged adults (ages 35$49 ; 9.5 \%$ ), older adults (age $>50 ; 2.9 \%$ ) and adults of indeterminate age (42.9\%) (Aldenderfer and Eng, 2016).

The tombs were used from ca. 420-860 CE, with most interments placed in the chambers between 420 and $680 \mathrm{CE}$. In this manuscript, we focus upon two chambers where the bulk of the metal objects were recovered: Samzong 5 (422-538 CE; median date $483 \mathrm{CE}$; Calib 7.1) and the combined chambers of Samdzong 1-4 (583-690 CE; combined median date of 647 CE; Calib 7.1). The artefacts from Samdzong 5 include copper cooking vessels and a cauldron, weapons such as iron daggers and decorative pieces such as a bronze medallion, and brass bangles. Hundreds of beads made of metal and glass were also found, some of them still attached to parts of the fabric (Gleba et al., 2016) that probably served as additional decoration of what is the most spectacular find: a gold and silver mask, with raised and pigmented facial features. These materials accompanied the burial of a single adult (sex not determined) in a painted wooden coffin. The finds recovered from Samdzong 1-4 lack the cooking or liquid storage vessels found in Samdzong 5, and the majority of objects recovered are related to horse tack, such as buckles, loops, leather straps with metallic buttons and medallions. Daggers and arrowheads are also present in large numbers, along with iron plates. Here, the dead were placed upon low wooden platforms as well as directly on the floor of the chamber. The assemblage also included two gold and silver masks. These, however, were crumpled into small lumps that unfolded to reveal their features. One was painted in a similar manner to that found in Samdzong 5 , while the other seems unpainted (Aldenderfer, in press). 


\section{Sample and methods}

The entire collection of metallic objects from Samdzong 5 was analysed during a field trip in May 2012 using a portable X-ray fluorescence spectrometer (pXRF). The production technology was assessed through macroscopic observation. A selection of samples covering the typologies of artefacts and alloy categories recorded on site was exported with the permission of the Department of Archaeology, Government of Nepal to the Wolfson Archaeological Science Laboratories at the UCL Institute of Archaeology to undergo analyses by wavelength dispersive electron probe microanalyser (EPMA) and scanning electron microscopy with energy dispersive spectrometry (SEM-EDS) in addition to further technological investigations using metallography. During this second stage, samples from Samdzong 1-4 were also made available for analyses, comprising fragments of two of the three masks and a piece of a medallion (Table 1).

Table 1. List of artefacts from different chambers at Samdzong.

\begin{tabular}{|c|c|c|c|}
\hline Sample cod & Descritption & Location & Material \\
\hline SMZ1-C2-1 & Mask & Samdzong 1 Chamber 2 Yes & $\mathrm{Ag} / \mathrm{Au}$ alloys \\
\hline SMZ1-C4-1 & Mask & Samdzong 1 Chamber 4 Yes & $\mathrm{Ag} / \mathrm{Au}$ alloys \\
\hline SMZ1-C4-2 & Medallion & Samdzong 1 Chamber 4 Yes & Bronze \\
\hline SMZ5-1 & Mask & Samdzong 5 & $\mathrm{Ag} / \mathrm{Au}$ alloys \\
\hline SMZ5-2 & Bead & Samdzong 5 & Copper \\
\hline SMZ5-3 & Cauldron & Samdzong 5 & Copper \\
\hline SMZ5-4 & Group of beads & Samdzong 5 & Brass/Copper/Iron \\
\hline SMZ5-5 & Small Vessel & Samdzong 5 & Copper \\
\hline SMZ5-6 & Ladle & Samdzong 5 & Copper \\
\hline SMZ5-7 & Rod & Samdzong 5 & Brass \\
\hline SMZ5-8 & Strip & Samdzong 5 & Brass \\
\hline SMZ5-9 & Bracelet & Samdzong 5 & Brass \\
\hline SMZ5-10 & Curved Rod & Samdzong 5 & Brass \\
\hline SMZ5-11 & Fragment & Samdzong 5 & Bronze \\
\hline SMZ5-12 & Mirror & Samdzong 5 & Bronze \\
\hline SMZ5-13 & Fittinga $^{a}$ & Samdzong 5 & Bronze \\
\hline SMZ5-14 & Plate $^{\mathrm{b}}$ & Samdzong 5 & Iron \\
\hline SMZ5-15 & Dagger ${ }^{b}$ & Samdzong 5 & Iron \\
\hline
\end{tabular}

a Fitting = Object probably attached to clothing or to a saddle.

b Iron pieces were sampled for metallographic examination, but the material was completely corroded. 
For the artefacts that were not sampled, the pXRF results are the only compositional data available. Additionally, iron artefacts, although completely corroded, were sampled hoping to find any remnants of slag inclusions but unfortunately none were found. The pXRF analyses were carried out using the factory-built Alloys mode of an Olympus Innov-X Delta Premium instrument, using a single beam at $40 \mathrm{kV}$ for $20 \mathrm{~s}$. Depending on the condition of the object, three to five readings were performed on spots that were mechanically cleaned, although it was impossible to completely remove all traces of patina in the chosen areas. Therefore, the results are deemed qualitative only.

For those objects investigated invasively, samples were embedded in epoxy resin and polished for metallography and microanalysis; copper alloys and the iron pieces were polished down to $0.25 \mu \mathrm{m}$ using diamond paste while the precious metals were prepared with alumina down to $0.05 \mu \mathrm{m}$. Metallographic examination followed standard procedures, including etching with aqueous ferric chloride for 2-8 s, depending on the condition of the matrix.

EPMA bulk compositional analysis was performed on the copper-base samples by reading five relatively non-corroded areas of $119.5 \mu \mathrm{m} \times 87.8 \mu \mathrm{m}$ per sample at $1000 \times$ using a JEOL JXA-8100 superprobe; each reading took $40 \mathrm{~s}$, and detection limits are around 0.01-0.05 for most elements. SEM-EDS was performed on the samples to investigate more flexibly the variability within the material by examining individual phases or inclusions. In addition, gold/silver samples could not be analysed by EPMA owing to an instrument breakdown and hence compositional results reported are from area analyses on the Hitachi SEM-EDS. Two electron microscopes were used for imaging and compositional analysis: a Philips XL30 ESEM and a Hitachi S3400 N, both with Oxford Instruments EDS systems, running at $20 \mathrm{kV}$, with a time of $100 \mathrm{~s}$, and detection limits around $0.1-0.3 \%$. Area analyses were employed for bulk compositions, and point analysis for the identification of smaller phases. All the SEM images included in this paper are from the backscattered electron (BSE) detector, where higher phase brightness correlates with a higher average atomic weight.

All the compositional data are reported in percentage by weight (wt\%). Analytical totals in SEM-EDS analyses may not equal to $100 \%$ due to instrumental error, matrix effects and fluctuations in beam intensity, and thus we opted to normalise them to $100 \%$ to facilitate comparisons, while analytical totals prior to normalisation are reported. For EPMA, we present unnormalised results following conventional practice. Lead isotope analyses (LIA) were performed at the Geochronology and Geochemistry-SGIker facility of the Universidad del País Vasco UPV/EHU (Spain). About $0.100 \mathrm{~g}$ of sample was digested overnight in nitric acid (HNO3) and evaporated to dryness. The residue is dissolved in hydrogen bromide $(\mathrm{HBr})$ and lead $(\mathrm{Pb})$ isolated by conventional ion-exchange chromatography (Anion exchange resin (AG1-X8) in $\mathrm{HBr}$ and hydrochloric acid $(\mathrm{HCl})$ media. The recovered lead was evaporated to dryness, dissolved in $0.32 \mathrm{eq} / \mathrm{L} \mathrm{HNO} 3$ and diluted to a final concentration of 150-200 ppb. Lead isotope ratios were measured with a Thermo Neptune multicollector inductively coupled plasma mass spectrometer (MC-ICP-MS), and the mass fractionation internally corrected after the addition of thallium isotopic reference material NBS-997 (Walder et al., 1993). Detailed protocols are similar to those described by Chernyshev et al. (2007). Precision and accuracy of the results are routinely monitored through analysis of certified material NBS-981. It is important to note that in our comparisons with reference data from the literature we use a variety of published datasets of variable quality, hence not following strict protocols of data quality (Stos-Gale and Gale, 2009, 203; Artioli and Angelini, 2010, 327). This is due to the very scant quantity of data readily available for Nepal and its surrounding regions, which forced us to use any data available. The data are mainly used to look for variability within the collection and for overall insights regarding the possible origins of the material, without attempting to pinpoint an individual source for the raw materials used in the production of our assemblage. 


\section{The artefacts: technology, composition and comparisons}

During the fieldwork completed in the spring of 2012 the artefacts from Samdzong 5 were observed and analysed by pXRF allowing the separation of the artefacts by metal or alloy as listed in Table 1 . The majority of the artefacts were sampled for further investigation and the results are presented in turn. Iron will not be included in the report given the corrosion observed in each of the samples, which precluded any meaningful investigation. The average bulk chemical compositions of the artefacts analysed invasively is reported in Table 2, Table 3.

Table 2. Average bulk composition by EPMA of the artefacts from Samdzong.

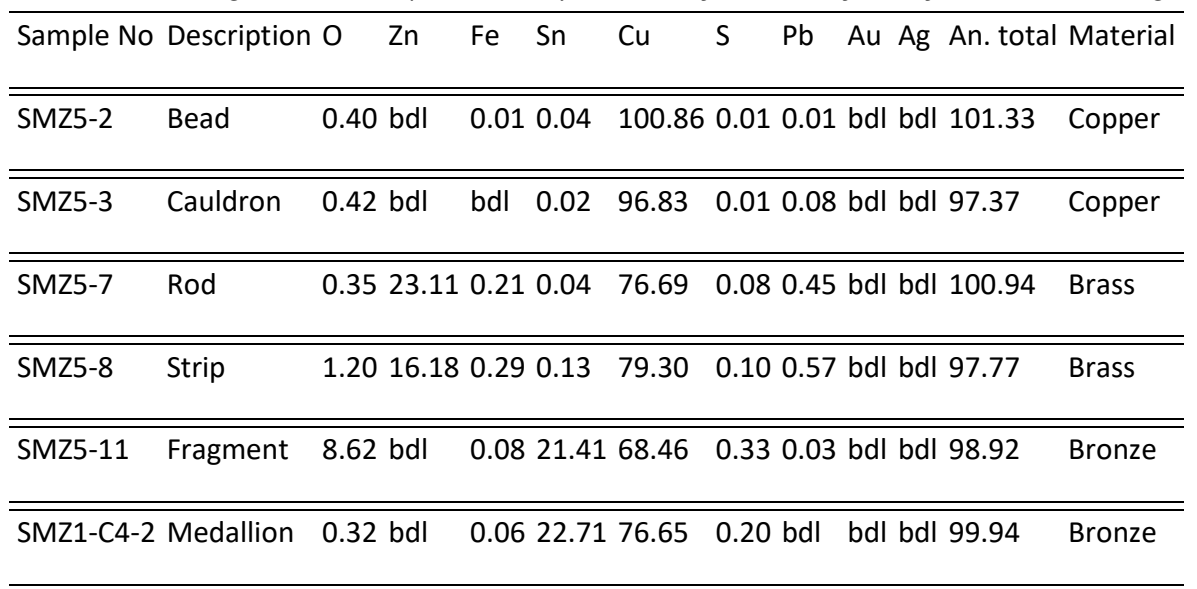

'bdl' = below detection limit.

Table 3. Average bulk composition by SEM-EDS of the various layers noted in the cross-sections of the silver and gold masks.

\begin{tabular}{|c|c|c|c|}
\hline Sample & $\mathrm{O} \quad \mathrm{Cl} \mathrm{Cu} \mathrm{Ag}$ & $\mathrm{Au}$ & An. total \\
\hline SMZ1 C4-1 front & bdl bdl 0.911 .6 & 887.5 & 102.1 \\
\hline SMZ1 C4-1 back & 0.60 .12 .0989 .5 & 7.7 & 110.3 \\
\hline SMZ1 C4-1 back surface & $1.8 \mathrm{bdl} 2.288 .4$ & 7.7 & 109.8 \\
\hline SMZ1 C2-1 front & bdl bdl 0.58 .3 & 91.2 & 102.1 \\
\hline SMZ1 C2-1 back & bdl bdl 1.488 .2 & 10.4 & 107.8 \\
\hline SMZ1 C2-1 back corrodec & | 0.78 .11 .1879 .7 & 10.4 & 108.2 \\
\hline SMZ1 C2-1 back surface & 1.67 .90 .5779 .4 & 110.6 & 105.3 \\
\hline SMZ5-1 front & bdl bdl 2.1226 .7 & 71.2 & 103.5 \\
\hline SMZ5-1 back & 2.7 bdl 3.4990 .8 & 3.1 & 97.7 \\
\hline SMZ5-1 back surface & 3.1 bdl 1.192 .1 & 3.8 & 98.2 \\
\hline
\end{tabular}

'bdl' = below detection limit.

The analysis confirms the variety of metals and alloys present at the site, with different alloys used for different artefacts. In particular, pure copper, brass, bronze, gold and silver alloys are found, in addition to iron. The variable amounts of oxygen detected in all the copper-base alloys are indicative of mild corrosion. 


\subsection{Copper}

The assemblage from Samdzong 5 includes three vessels made of pure copper: a ladle, a bowl and a large cauldron (Fig. 3a), from which sample SMZ5-3 was taken. All the artefacts showed visible hammering marks. The cauldron is made of two halves joined together in the centre by a strip of metal and several rivets (Fig. 3b). A similar band is used on the mouth of the vessel as a rim. Rivets are also used to hold in place a small plate at the bottom of this vessel, which suggests the repair of an object that was used before being deposited. The microstructure of this object shows a fully recrystallized structure with annealing twins, indicating a full annealing process or hot working as the last manufacturing step. Cuprite globules were the only discrete inclusions noted, which is consistent with the remarkable purity of the metal (Fig. 4).

a)
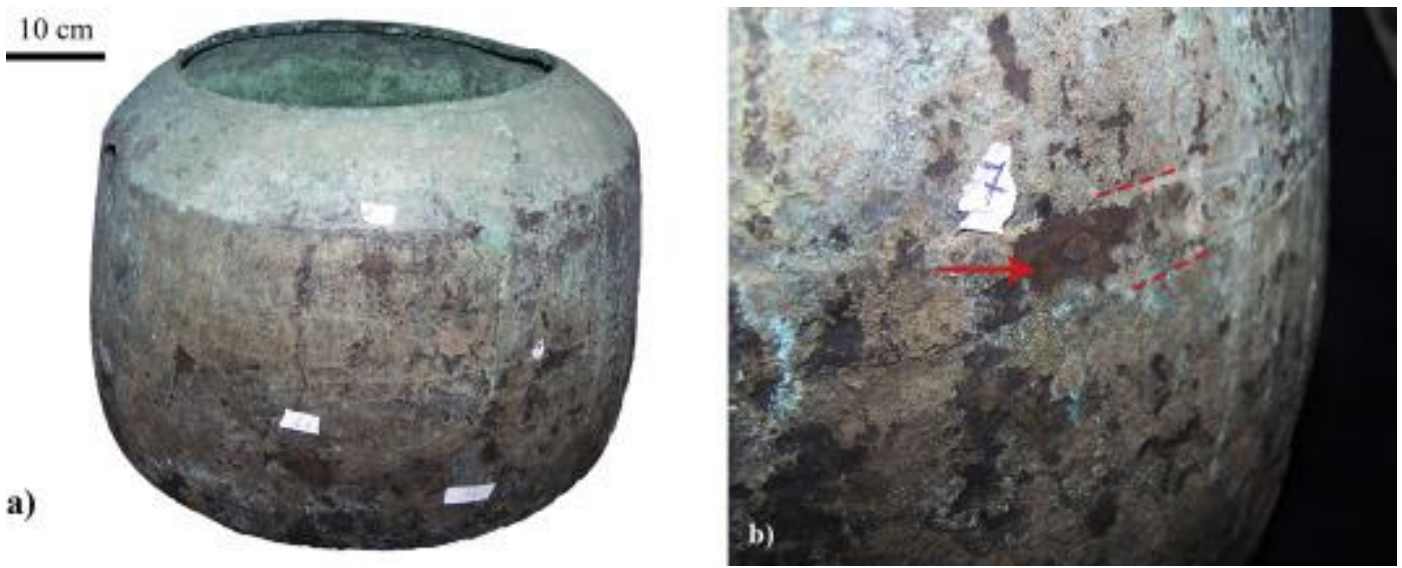

Fig. 3. a) Copper cauldron from Samdzong 5. b) Detail of a rivet used to join the two halves of the vessel. A strip (between dashed lines) is used to reinforce the joint. (Photo: G. Massa).

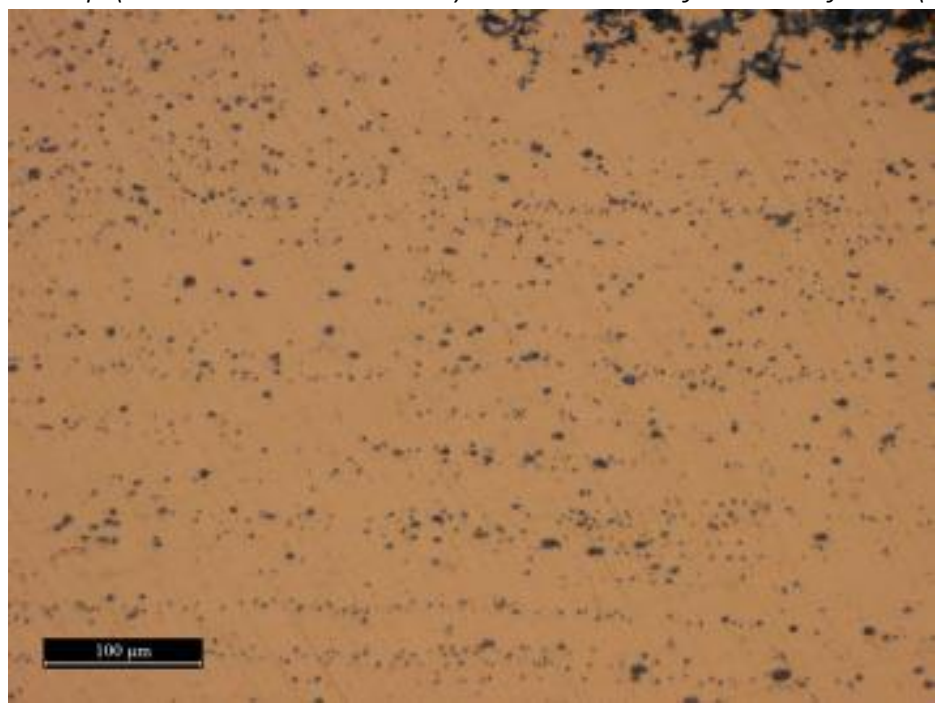

Fig. 4. Rounded and aligned cuprite $\left(\mathrm{Cu}_{2} \mathrm{O}\right)$ within the copper matrix of the vessel SMZ5-3, unetched.

In addition, at least some of the many tubular beads recovered at the site are made of pure copper (Fig. 5), also hammered and annealed, as is indicated by the analysis of sample SMZ5-2. However, surface pXRF results indicate that brass beads (SMZ5-4) may be present too. These beads are made of a thin sheet of metal, rolled into tubes ca. $1 \mathrm{~cm}$ long and $0.2 \mathrm{~cm}$ diameter, with no soldering. They appear together with glass beads and are attached to textiles (Gleba et al., 2016). 


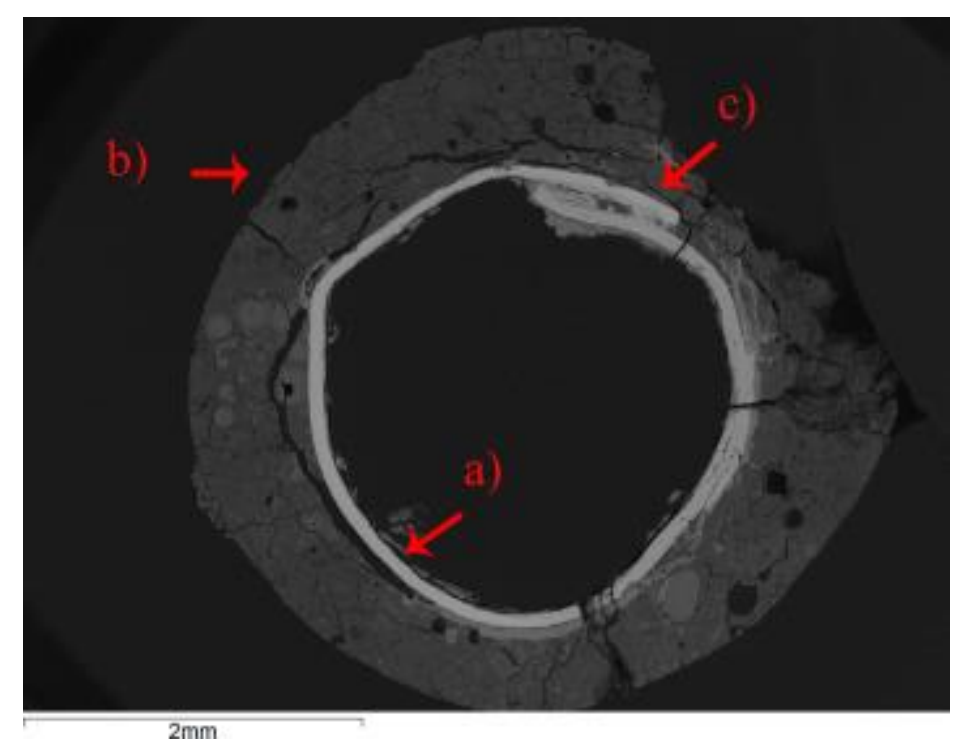

Fig. 5. SEM - BSE image of a cross-section through copper bead SMZ5-2. The solid metal (brighter band $-a$ ) is surrounded by corrosion (darker band $-b$ ). The overlap on the joint without soldering (c) is visible near the top right corner.

Copper ores are present in northern India, Sikkim in the east and Kashmir in the west (Brown and Dey, 1955, 146-153). Both Nepal and Tibet have copper mines, but their archaeology has not been researched. Nepal is mentioned in an 11th century CE treatise a source of high-quality metal (Lo Bue, 1981, 37), whereas Tibetan copper mines are first mentioned in the 18th century by the Italian Capuchin, Father Orazio della Penna di Billi (Lo Bue, 1981, 40). Additionally, Hindu and Buddhist unalloyed copper statues from Nepal dating as early as the 7th century CE have been described and analysed (Reedy, 1997).

Considering the results of lead isotope analyses (reported below), we can tentatively suggest an Indian origin for the material, at least for one of the artefacts - the copper bead; however, the lack of data from Nepal and Tibet makes this conclusion tentative.

The beads from Samdzong are typologically comparable to those recovered at the nearby site of Chokhopani East, dating to the 6th century CE (Simons et al., 1994). Of more interest are the comparanda for the copper vessels (Fig. 6), as their technology and typology are typical of the Indus valley. At the site of Taxila, copper vessels dating to the 1st century CE are invariably made of two halves hammered and riveted together (Marshall, 1951). The plain shape and simple technology are in contrast with the more complex vessels known from China or the Middle East, and the tradition has deep roots in the Harappan tradition of beaten metal vessels (Agrawal and Seshadri, 1998, 10; Biswas and Biswas, 1996, 184; Rao, 1985). 

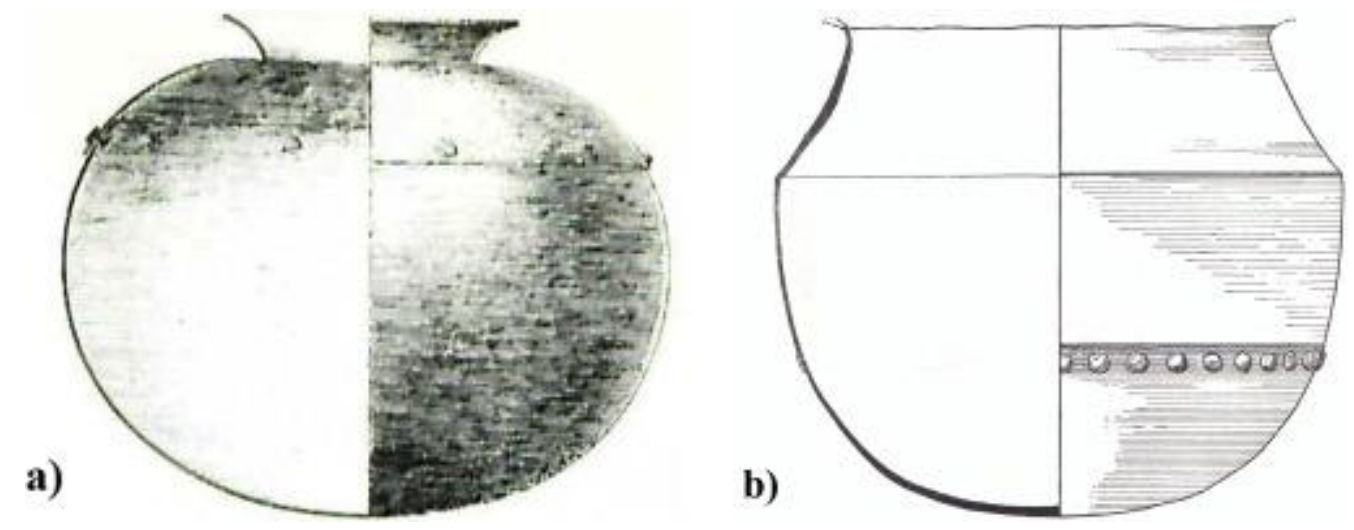

Fig. 6. a) Copper vessel from Taxila (Marshall, 1951, plate 174). Height $24 \mathrm{~cm}$ b) Copper vessel from Lothal (Rao, 1985, fig. 119 page. 554 Vol. 2). Date: $1895 \pm 115$ BCE. Diameter c. $35 \mathrm{~cm}$. In both cases, the vessels are made of two hammered parts and then riveted together.

\subsection{Brass}

At least three objects and three additional fragments from Samdzong 5 are made of brass. The first group consists of a brass bangle (Fig. 7a) and two curved rods that might be part of bracelets or necklaces. In section, they are almost semi-oval, suggesting that they were shaped out of a bar cast in a mould, and simply decorated with parallel transverse incisions (Fig. 7b). The latter group includes thin fragments, ca. $0.5 \mathrm{~mm}$ in thickness, from an almost completely corroded strip of metal.
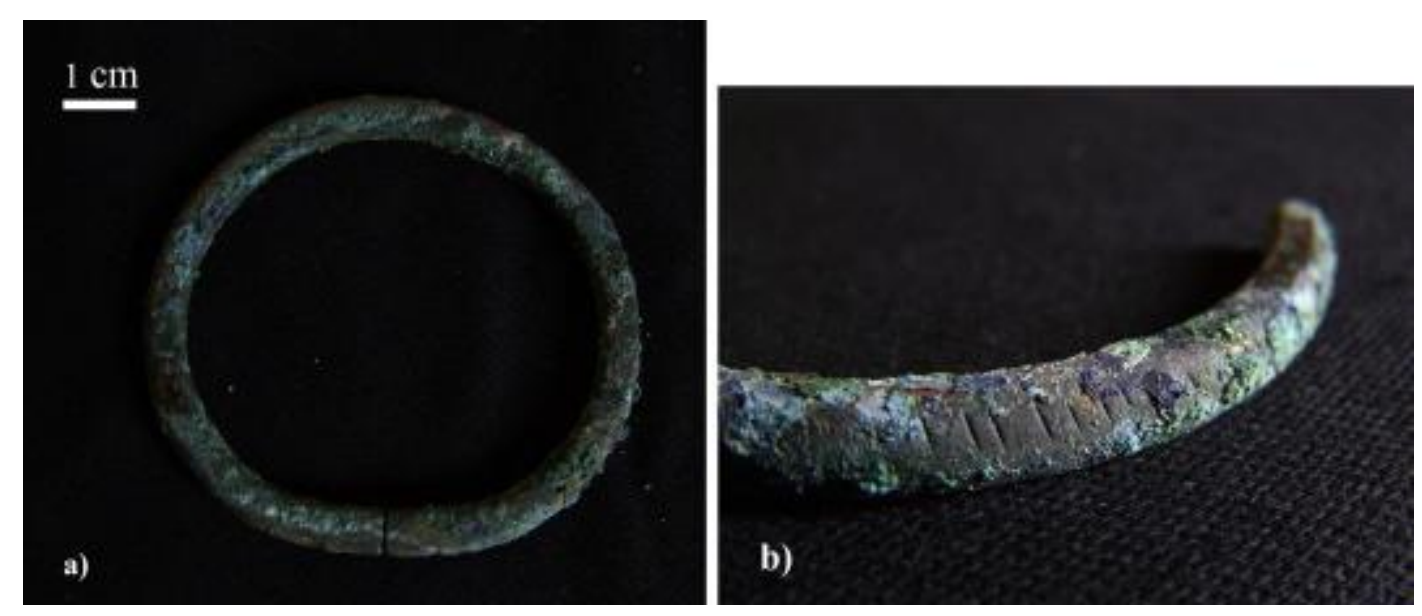

Fig. 7. a) The bangle SMZ5-9 seems the only complete piece of the group of brasses, with an internal diameter of $6 \mathrm{~cm}$. The thickness of the rod in all the objects is ca. 3 to $4 \mathrm{~mm}$. b) Brass rod showing details of the decoration with small indentations. (Photo: G. Massa).

Rod fragment SMZ5-7 is a brass alloy with $23 \% \mathrm{Zn}$. The zinc content as measured in sheet fragment SMZ5-8 is $16 \%$, but the original alloy may have been more zinc-rich: zinc could have been lost during intensive hammering and annealing (Caley, 1964, 99), as well as by dezincification during postdepositional corrosion (Samans, 1963, 241). The microstructure of the rod shows equi-axed twinned grains (Fig. 8) as well as surface strain lines, probably related to the incised decoration, and intergranular corrosion towards the more porous core. The main inclusions in the metal are lead globules, together with occasional $\mathrm{Cu}-\mathrm{Zn}-\mathrm{S}$ inclusions. The sheet is more corroded, but it shows a tight fibrous structure that denotes intense hammering (Fig. 9a-b). 


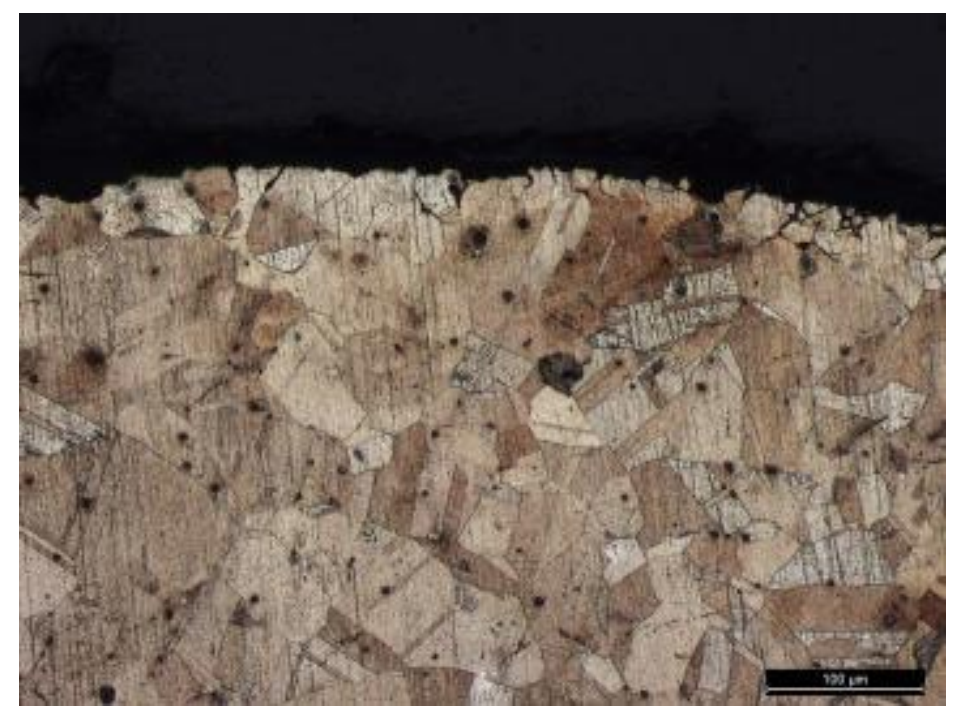

Fig. 8. Etched edge of the brass rod SMZ5-7 showing large equi-axed grains with straight twins.

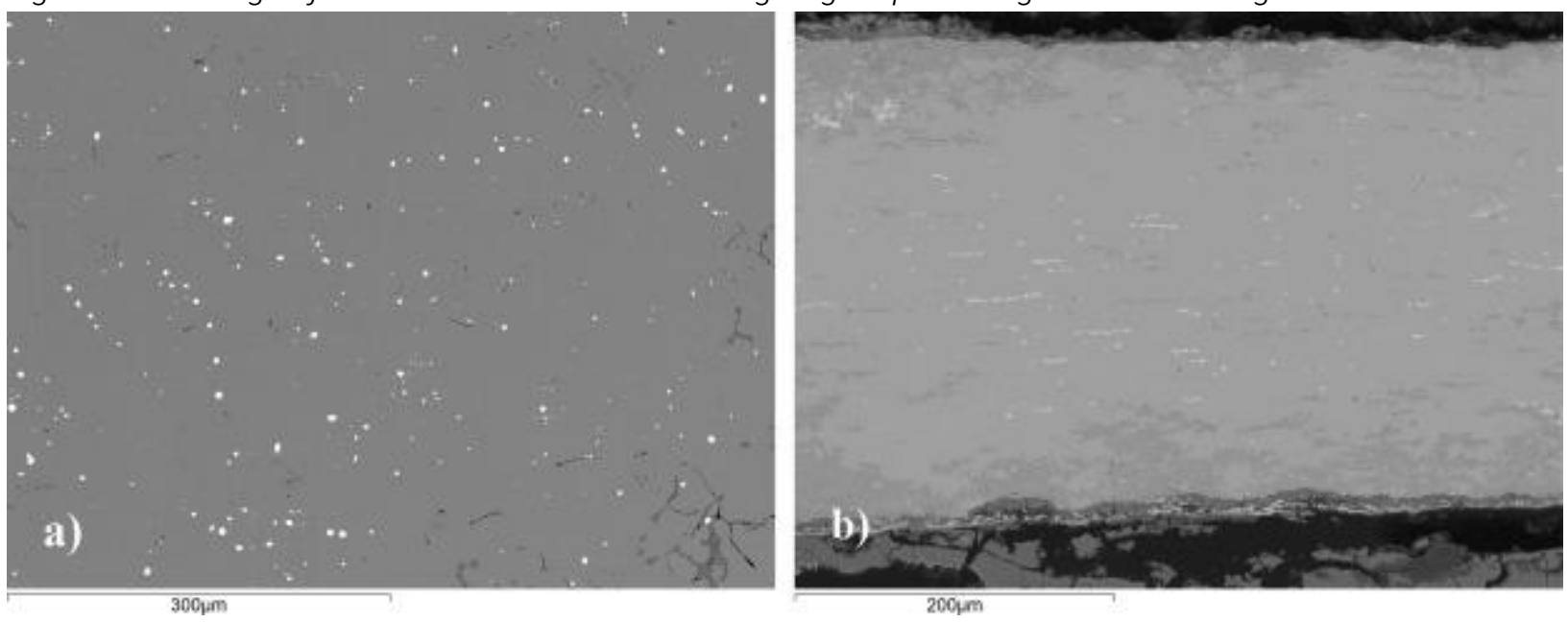

Fig. 9. a) SEM - BSE picture of lead in brass rod SMZ5-7; rounded and evenly distributed. b) BSE picture of brass strip SMZ5-8. In this case lead is found in elongated phases also concentrated on the surface; a white band is particularly evident on the lower end of the picture.

EPMA analyses showed low levels of iron, tin, sulphur and lead in both brass samples. Premodern brasses were made by cementation of metallic copper with zinc oxide and charcoal in a crucible: metallic zinc vapour was produced, which readily alloyed with the copper. The low levels of impurities in the metal are indicative of brass produced by cementation of copper with the roasted zinc sulphide ore sphalerite. The alternative zinc ore, the carbonate sometimes known as smithsonite, tends to lead to more impure brasses, with iron levels around $0.5 \%$ or higher (Craddock et al., 1998, 78; Craddock, $1979,70)$. On this basis, it can be suggested that the brass recovered in Samdzong comes from either the Middle East or India, where sphalerite is more common. The fact that these brasses are unleaded ( $0.5 \% \mathrm{~Pb}$ is considered an ore impurity rather than a deliberate addition) makes them more consistent with an Indian and Nepalese tradition, where the absence of deliberate additions of lead is characteristic (Craddock, 1981, 23). Identifying brasses comparable to those in Samdzong is not easy, not least because analyses of early brasses in the area are limited, and typically focused on cast sculptures (e.g. Craddock, 1981; Lo Bue, 1981; Reedy, 1997; Sharma, 2004). The most relevant comparable material comes from the Pakistani site of Taxila, where brass is believed to have first been introduced from the West and then produced locally by copying Hellenistic objects (Craddock, 1981, 
11). The brass objects of Taxila, dated to the 4th century CE are considered the earliest in India (Marshall, 1951, 570). The assemblage from the site includes incised brass bangles of identical typology to those recovered in Samdzong (Fig. 10a-C), and limited analytical data indicates variable lead levels but consistently low traces of iron and tin (Marshall, 1951, 568). Brass artefacts are said to have been found in Chokhopani East (Simons et al., 1994).

In summary, in both the style and composition, the brass artefacts from Samdzong are similar to northern Indian metallurgical traditions.
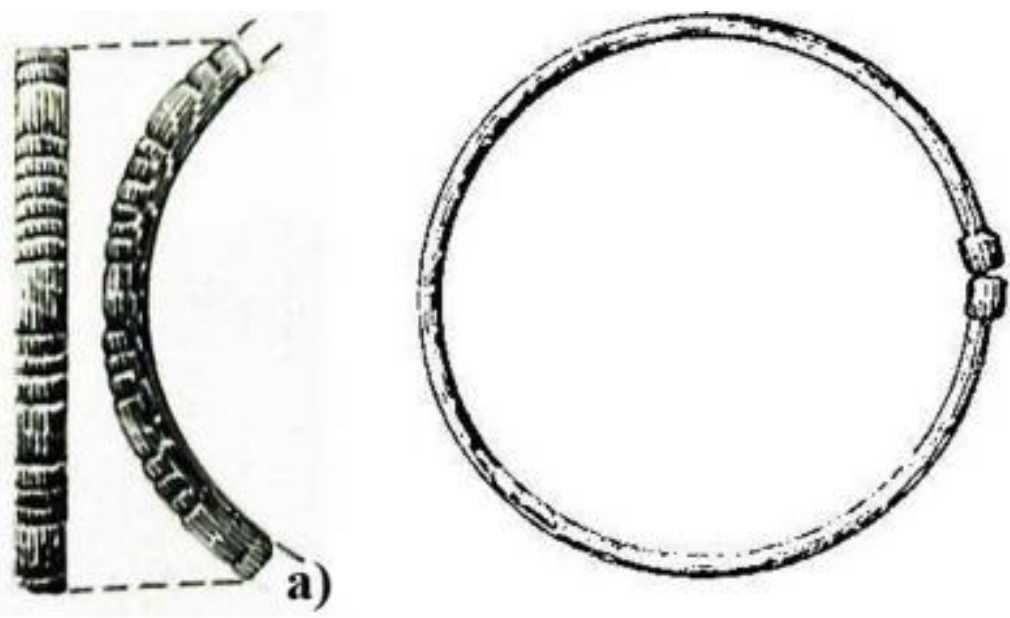

b)

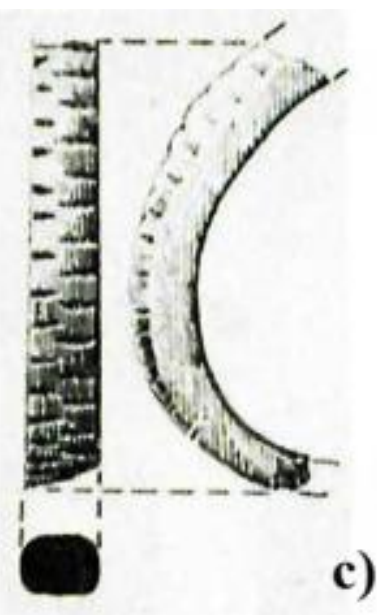

Fig. 10. Bracelets from Taxila. $a$ \& b) Bracelets made of copper alloys, the bangle with the open end to allow the bracelet to fit the arm and the incised decoration reminds to the Samdzong objects. (Marshall, 1951, Plate 171 VOL III) c) Decoration of a shell bracelet. This decoration is more similar to the Samdzong objects, with plain incision as if imitating beads. (Marshall, 1951, Plate 201 VOL III).

\subsection{Bronze}

Bronze artefacts were found in both mortuary contexts. From Samdzong 5 there is a group of corroded fragments forming a "tube" (SMZ5-11), in addition to a medallion or mirror (SMZ5-12) and an unidentified cast "fitting" (SMZ5-13) - probably a piece of horse tack (Fig. 11a-c). Surface analyses of the latter object showed the presence of both zinc and tin, suggestive of a recycled alloy. The mirror SMZ5-12 is $8 \mathrm{~cm}$ in diameter and ca. $4 \mathrm{~mm}$ thick. It can also be described as a medallion since it has an off-centred perforation near the edge, now filled by corrosion products, which could have served for hanging. However, the hole could also be the point of or the attachment of a handle. One side is plain, while the other is decorated by a set of lines forming concentric circles and semi-circles, in addition to punched dots and squares also in circular arrangement. Although the object could not be analysed invasively, its surface features suggest that it was cast in a mould on which the main decoration patterns were carved, although these were supplemented with punching. Surface pXRF analyses of several spots indicate an unleaded high tin bronze, with tin levels around 30\%. However, as mentioned in our methodology, we can only consider this result as qualitative due to the nature of the analysis itself. Furthermore, a superficial analysis cannot rule out any surface enrichment of tin that may occur due to either the techniques used to make the artefact or to corrosion (Meeks, 1986). 

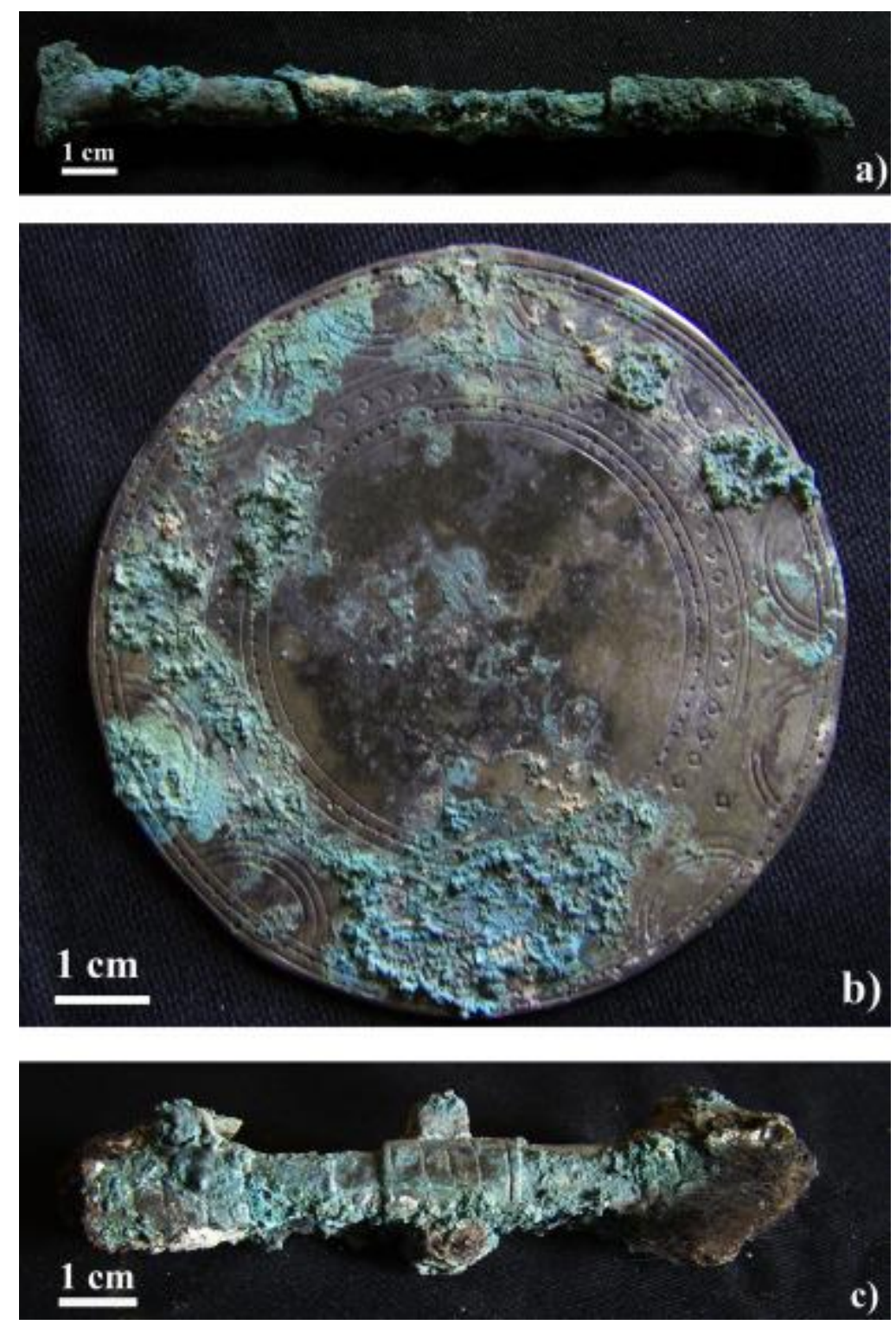

Fig. 11. Bronze artefacts. a) SMZ5-11 Tubular piece reconstructed from matching fragments. b) SMZ512 Medallion with incised and stamped decorations. On the top a pear-shaped hole is filled with corrosion. c) SMZ5-13, clothing or horse tack fitting with linear incisions. Remnants of fur are still attached to the piece. (Photo: G. Massa).

The only bronze from Samdzong 1-4 available for study is a fragment of what may have been an additional medallion or mirror (SMZ1-C4-2) which is approximately $6 \mathrm{~cm}$ in diameter and $3 \mathrm{~mm}$ thick. In these cases, EPMA analyses of both the tube fragment SMZ5-11 and the medallion fragment SMZ1C4-2 showed them to be unleaded high tin bronzes, with tin levels exceeding $21 \%$ and negligible levels of impurities: other than copper and tin, sulphur is the only element detected above $0.1 \%$. However, corrosion in SMZ5-11 renders these results less reliable. The microstructure of the medallion shows remnants of $\alpha$ phase with twinned crystals, within a martensitic matrix of $\beta$ phase, in addition to elongated sulphide inclusions (Figs. $12 b$ and $13 a-b$ ). This metallographic structure is typical of a high tin bronze that has been hot worked and quenched (Murillo-Barroso et al., 2010; Scott, 1991, 26). The microstructure of fragment SMDZ5-11 (Figs. 12a and 14) can only be inferred by the ghost structure left by the corrosion process. The material consists of high tin bronze with $\alpha$ grains surrounded by $\delta$ 
phase grains. The equi-axed shape of the copper rich grains might indicate, along with the absence of dendrites or twinning, that the material was cast and slowly cooled down.

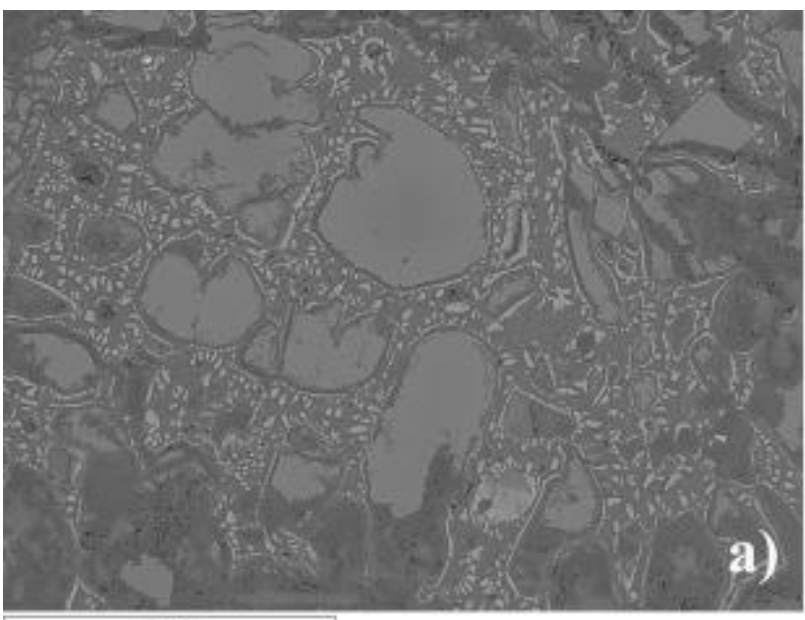

$100 \mathrm{~mm}$

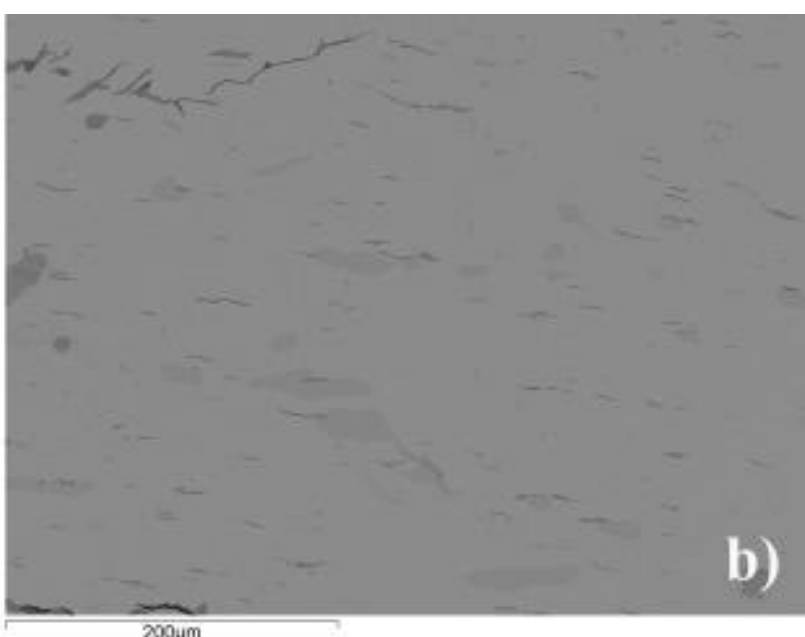

$200 \mathrm{jm}$

Fig. 12. a) Bronze fragment, SMZ5-11; BSE picture of $\alpha$ phase (large grains) surrounded by small $\delta$ phase (bright grains) embedded in a corroded $\alpha+\delta$ eutectoid matrix (dark grey background); b) Sample SMZ1C4-2 - fragment of bronze mirror or medallion; BSE picture of $\alpha$ phase grain embedded in a $b$ matrix. Small, elongated sulphides are also present.
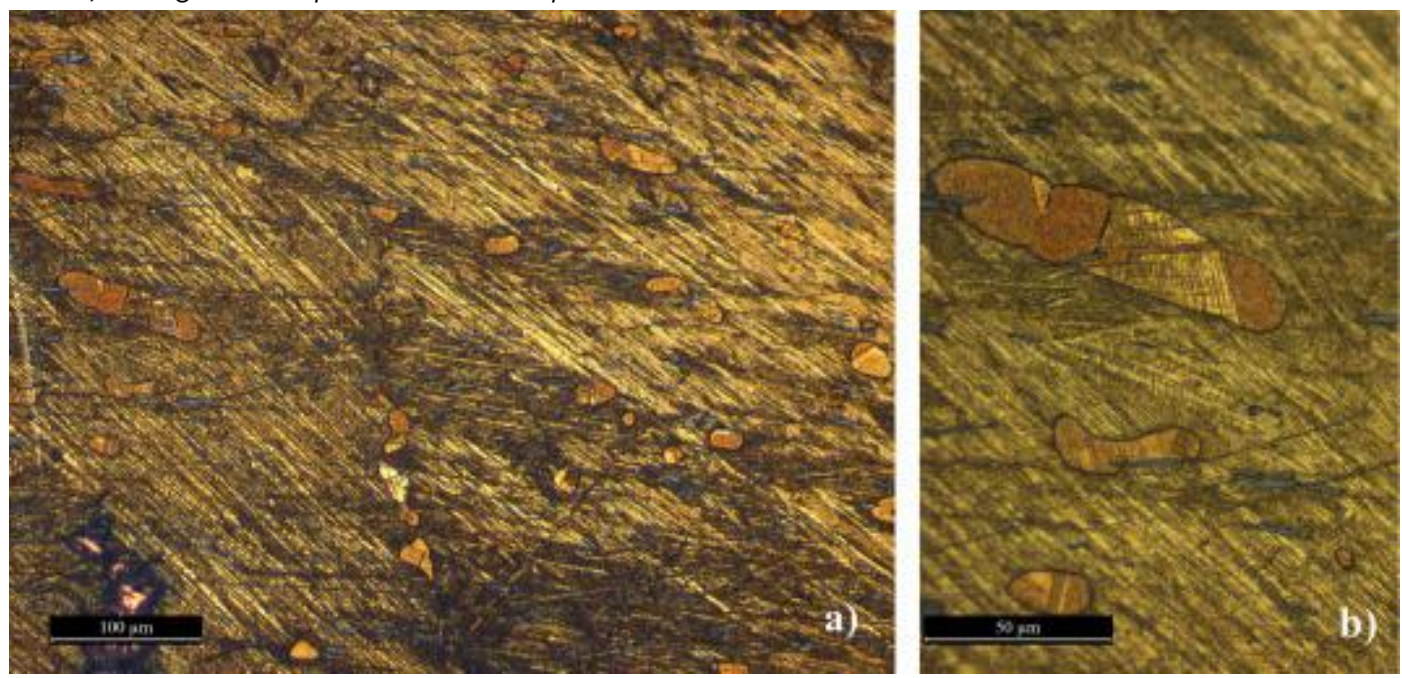

Fig. 13. SMZ1-C4-2, bronze medallion a) Plane polarised light (PPL) picture showing aligned a phase embedded in a martensitic matrix. The phase is aligned along with the elongated grey sulphides. b) The structure of the matrix is found after quenching while twinning and strain lines indicate hot working followed by additional cold working. 


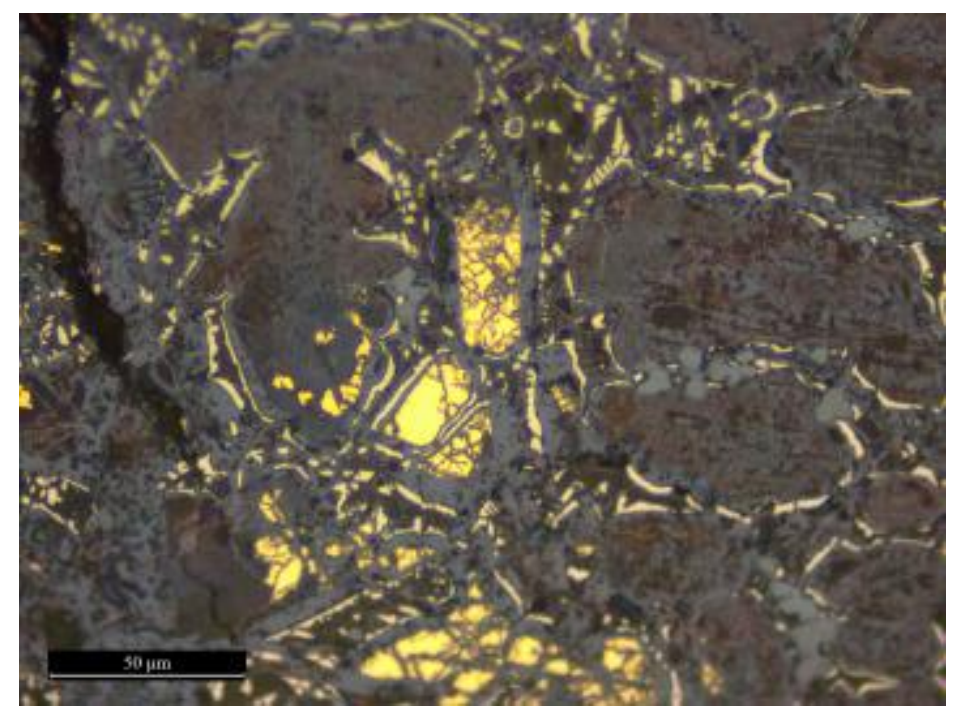

Fig. 14. Plane polarised light (PPL) picture of bronze sample SMZ5-11. The material is almost completely corroded with the $\delta$ phase left surrounding corroded equi-axed $\alpha$ grains.

A few vessels from the Gurugyam cemetery in Tibet are made of high tin bronze (Institute of Archaeology - CASS, 2014, 583). However, there are no known sources of tin in Nepal and Tibet (Lo Bue, 1981, 34), therefore either the metal or the finished artefacts must have been brought to Samdzong from elsewhere. At the same time, making bronze objects with such high tin contents requires specialised skills, as they are particularly brittle and can only be forged while hot. Subsequent quenching, as recorded for the medallion, retains the $\beta$ phase and decreases the brittleness of the finished object (Scott, 1991, 26), hence providing a hard and shiny metal that can be highly reflective, especially after polishing (Cahill, 2009, 20). Altogether, material, technology and style evoke a probable foreign origin for the Samdzong bronzes.

High tin bronzes have been documented in several regions of Asia, including China (Barnard, 1961; Mei et al., 2015), India (Srinivasan, 1994, Srinivasan, 1997, Srinivasan, 1998, Srinivasan, 2010; Ranganathan et al., 2010), and Thailand (Murillo-Barroso et al., 2010), where geological tin sources are well-known. Archaeological evidence for tin mining and smelting is scarce (but see Srinivasan, 1997 for India and Murillo-Barroso et al., 2010 for Thailand), probably due to the alluvial nature of the tin ore cassiterite $\left(\mathrm{SnO}_{2}\right)(\mathrm{Babu}, 2003,179)$. An occasional observation on early tin smelting in Thailand was reported in the late 19th century, however this referred to a much later period (Bronson and Charoenwongsa, 1994, 15). Unlike those at Samdzong, Chinese mirrors tend to be made of ternary alloys containing lead (Barnard, 1961), whereas in India there is a long technological tradition of work with unleaded bronzes bearing exceptionally high tin levels (Srinivasan, 1998, Srinivasan, 2008, Srinivasan, 2013).

Circular mirrors are well known from early historic China. Those contemporary to the Samdzong example tend to have a circular knob and bear different decoration patterns in addition to the compositional differences noted above (Fig. 15a-b). Earlier Chinese mirrors, however, sometimes show combinations of concentric circles and arcs that are broadly comparable to that from Samdzong. This is especially true of Western Han (206 BCE - 9 CE) "Sunlight or illumination mirrors" (Wong, 2001, 61) and later examples found in Korea, where they are thought to relate to the solar worship derived from the steppe (Horlyck, 2011, 123-124). Similar mirrors have also been found in other locations in Southeast Asia, such as Cambodia or Vietnam (Pryce et al., 2014, 290). The use of mirrors for religious and apotropaic purposes is documented in northern and central Asia since the Bronze Age and it 
continues into the first millennium CE (Baumer, 2012, 187; Martynov, 1991, 69). Some of the later examples, for instance those recovered at the Stepnovo hoard in Siberia, also bear a central knob and are remarkably similar to the Samdzong mirror in their decorative design (Fig. 16). It can therefore be proposed that the ritual use of highly reflective mirrors or medallions may have been transferred to the Himalayas from Central Asia before Buddhism. As a potential precursor to this, small mirrors dated to the first half of the first millennium CE have been recovered in the Changtang of northern Tibet, and they were tentatively connected to the Tashtyk culture of the Inner Asian steppes (Bellezza, 2008, 105). These predate the Buddhist mirrors which are decorated with figurative incisions on the reflective surface (e.g. Lai, 2011). Other specimens very similar to the medallion found at Samdzong have been discovered on the Tibetan plateau, but their provenience is uncertain (John Bellezza, personal communication, December 2018).

In summary, the mirror/medallion SMZ5-12 might be related by its style to Central Asian traditions instead of Chinese ones; its composition and technology are reminiscent of Indian metalwork, although we should acknowledge that we know very little about the composition and technology of Central Asian high tin bronzes. For the other bronzes in Samdzong it is harder to suggest cultural or technical influences.
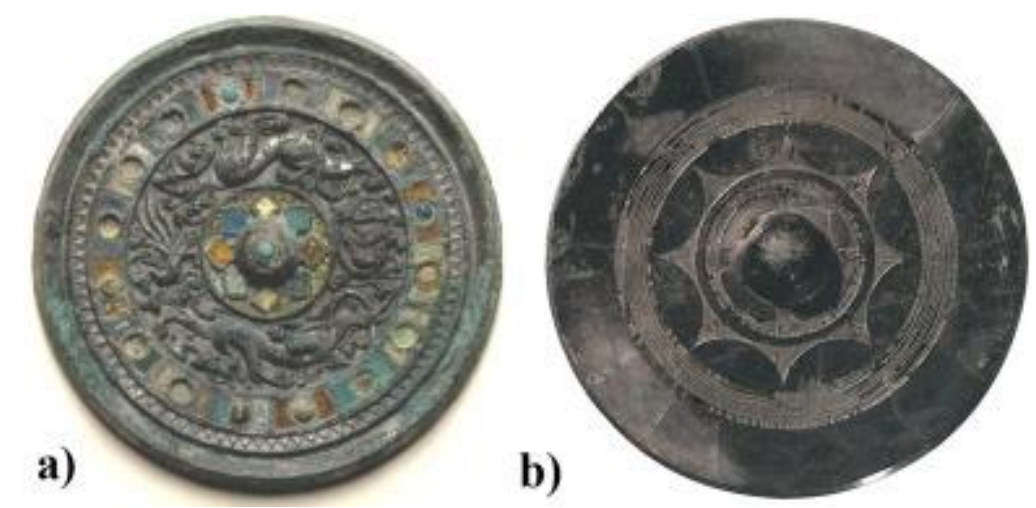

Fig. 15. a) Sui dynasty (420-618 CE), diam. $15.6 \mathrm{~cm}$. Example of mirror from the same period as SMZ512, cast animals and glass decoration make it different from SMZ5-12 (Cahill, 2009, PI. 80). b) Korean mirror from 3rd century CE, diam. 22,8 cm (Horlyck, 2011, 124). The decoration reminds of the indigenous worshipping of the sun. It is similar to Han mirrors and recalls the circle and arches of SMZ512. 

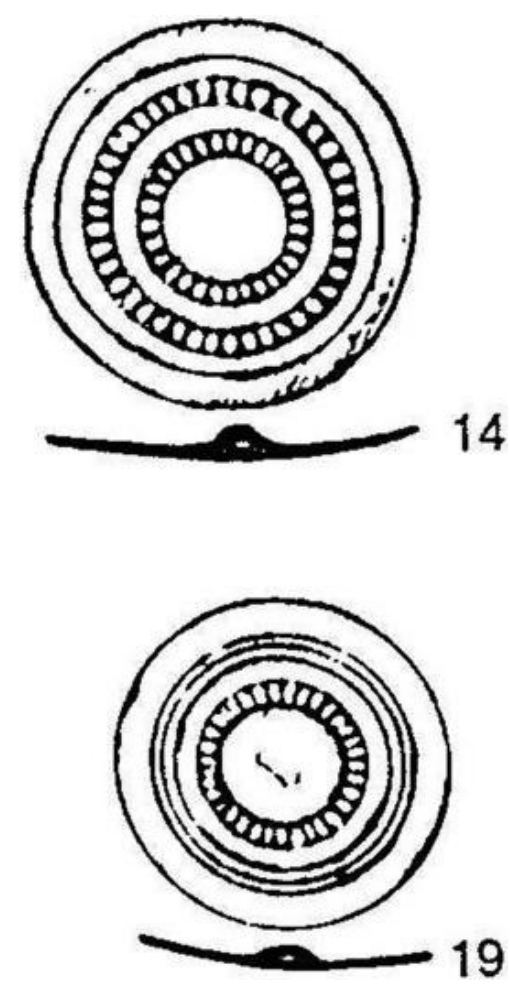

Fig. 16. Bronze Solar Badges representing circles or grain seeds from Siberian Stepnovo Hoard. Late first millennium BCE (Martynov, 1991, fig. 105).

\subsection{Gold and silver}

Very light and thin masks made of precious metals were recovered from both Samdzong 5 and 1-4 (Fig. 17a-e). These consist of sub-trapezoidal sheets of metal with thicknesses of only ca. 50-70 $\mu \mathrm{m}$. In each case, the mask is made of two extremely thin foils of metal bonded to each other: a gold-rich alloy at the front, and a silver-rich one at the back. The mask from Samdzong 5 (SMZ5-1) shows an embossed nose as well as facial features outlined by a combination of red (identified as cinnabar by SEM-EDS) and black pigments (presumably carbonaceous, since no heavy elements were detected). It shows small perforations around its entire outline, generally preserving the burrs, and suggesting that the mask may have been sewn onto an organic substrate or fabric. The other two masks (SMZ1 C4-1 and SMZ1 C2-1) are in a worse state of preservation because they were found folded into small, angular lumps. However, they show broadly similar features, including the use of red and black pigments and the perforations. Interestingly, mask SMZ1-C4-1, has a swastika painted on the left cheek. The other piece from Samdzong 1 (SMZ1-C2-1) had a similar trapezoid shape and showed traces of pigments, however the facial features are not visible. 


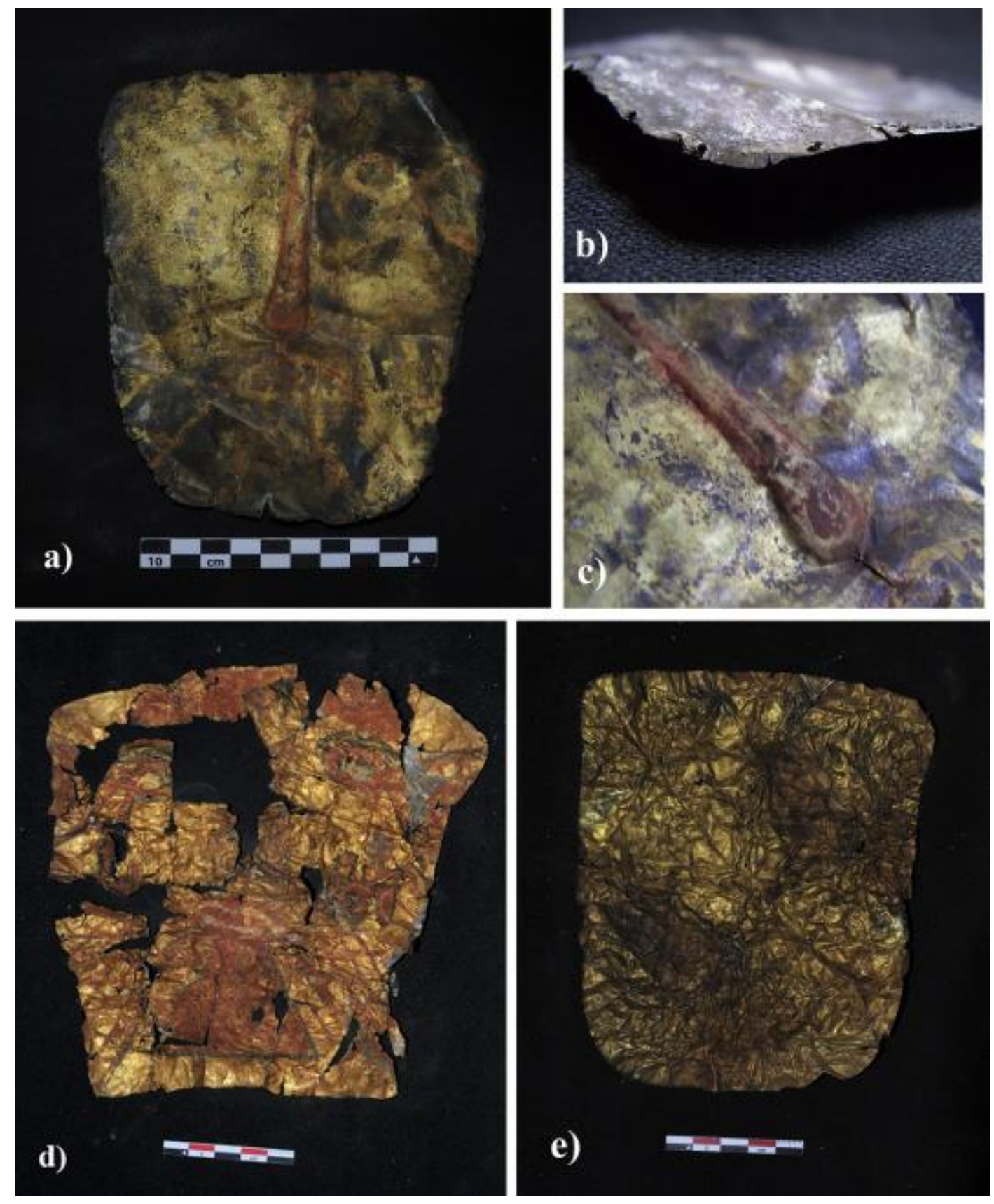

Fig. 17. a) Mask SMZ5-1 before sampling. The piece is trapezoid in shape, $15.5 \mathrm{~cm}$ wide and $12.3 \mathrm{~cm}$ long, with golden front and a silvery back reflecting the respective abundance of gold or silver in the alloys used. b) SMZ5-1, Holes that surround the artefacts were probably used to attach the piece to a cloth. c) SMZ5-1, facial features were shaped via repoussé or by the addition of red and black pigments. d) Mask SMZ1-C4-1; pigments were extensively used to draw the face. A red swastika was also depicted on the cheek. The silver back of the mask is visible where the gold layer has flaked off. e) Mask SMZ1C2-1; this piece shows use of pigments; however, any decorations or features are no longer visible. (Photo: G. Massa and M. Aldenderfer).

Cross-section analyses from the edges of the masks revealed the gold layer slightly wrapping the silver one, creating a golden rim on the silvery back. The silver layer is around $40-50 \mu \mathrm{m}$ in thickness, whereas the gold layer is even thinner, at around 15-30 $\mu \mathrm{m}$. In the samples examined, there is generally a good bond between both layers: even though there is a relatively sharp interface between 
both metals, slight intergranular corrosion in some areas of SMZ1 C2-1 shows the growth of annealing crystals across the interface between layers (Fig. 18a). Given the nobility and malleability of both metals, it would have been possible to hammer-weld both layers even without extensive heating (Oddy, 1991, 29; Oddy et al., 1981, 240). However, some parts of the folded masks show patches where the gold and silver have detached from each other. On the back (silver-rich) surface, a network of micropores can be noted in all three masks, typically corresponding to slightly lower copper levels: this probably reflects the depletion of copper by oxidation during annealing (Fig. 18b).
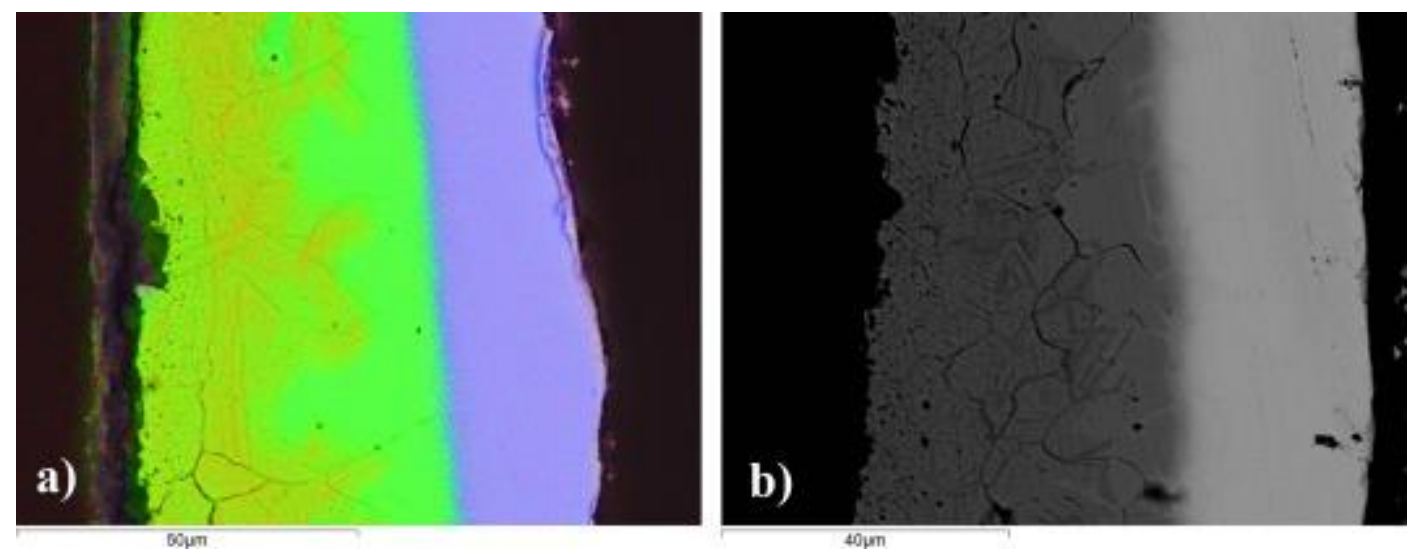

Fig. 18. a) Elemental Map of SMDZ1-C2-1. Intergranular diffusion seems to be present along the boundary between the silver-rich and the gold-rich side. This mask in particular was also found with a degree of corrosion on the silver side due to chlorine. Legend: Purple $=A u$; Green $=A g, \operatorname{Red}=C l$. b) BSE picture with gold diffusion between silver grains. Porosity is also visible on the surface of the silver layer.

The composition of the gold-rich layer reveals alloys with silver levels ranging $8-26 \%$ and $0.5-2 \%$ copper, whereas the silver layer contains $3-10 \%$ gold and $1-3 \%$ copper. While we cannot be completely conclusive about this point, it is likely that both layers represent artificial alloys. Starting with the gold, silver impurities can reach up to around $20 \%$ in gold from subvolcanic deposits, but copper levels rarely exceed $1 \%$. Thus, while the values for the SMZ1 masks are within plausibly natural levels, the gold composition for SMZ5-1 would be highly unusual. There is a positive correlation between the silver and copper levels in the three gold layers, which suggests that copper could have been added to the alloy together with silver. As for the silver, the levels of copper and gold are again higher than typical of natural, unalloyed silver (Rehren et al., 1996), and there is a positive correlation between copper and silver (albeit at different proportions than recorded for the gold-rich layer). It is interesting to note that the colour, hardness and melting point of the alloys recorded here are not significantly different from those of the parent metals (i.e. pure gold and silver). Overall, therefore, it would seem that the peculiar and variable compositions are the result of recycling rather than deliberate alloying. Also worthy of discussion is the reason that might have led the artisans to combine two layers of different alloys into a single mask. It would be tempting to think that the silver backing could have been intended to increase structural strength while saving on gold; however, other materials could have served this purpose more efficiently, and we should bear in mind that the actual amounts of both metals are very small in any case - they are simply stretched very thinly.

There are placer deposits of gold in Nepal in the Kali Gandaki Valley (Environment and Development Division (EDD), 1993), and western Tibet has both primary and placer deposits (Lo Bue, 1981, 54). Placer deposits are also the main gold sources in Northern India, Pakistan, Kashmir and Myanmar (Brown and Dey, 1955, 134; Allchin, 1962, 196). However, it remains impossible to suggest the possible gold source for the Samdzong masks with any precision, especially as we do not even know the natural 
composition of the gold. It should be noted that lead isotope analyses will probably reflect the isotopic signature of any copper added to the alloy, or that of the silver, rather than that of the gold itself.

As for the silver, argentiferous lead ores are known in Nepal and Tibet, but there is no evidence of their exploitation in ancient times. There have been reports of silver ores worked in eastern Tibet, however those happened at a much later date and they resulted in a negligible output of material. It appears that silver was mainly imported into Tibet from China, Mongolia and Siberia (Lo Bue, 1981, 53). Conversely, there is extensive evidence for the extraction of silver in the Aravalli Hills of Rajasthan, northern India, peaking in the second half of the first millennium BCE (Craddock et al., 2013). Other silver sources, from central and northern Asia through China and to Pakistan, are plausible but less likely. Lead isotope analyses are again of limited help here: even leaving aside potential problems of mixed recycling, the isotopic ratios may reflect the signature of the added copper or, more likely, that of the lead used during cupellation of the silver, which may or may not derive from the same geological deposit as the silver itself.

The nearest examples of pigmented funerary gold masks published so far come from the Chuvthag and Gurugyam cemeteries from western Tibet. These have been connected by Chinese scholars to the Zhang Zhung polity, which controlled much of western Tibet until its occupation by the Tibetan state in the 7th century CE (Tong and Li, 2016). These masks are thought to date to the 1st-2nd century CE. The mask from Gurugyam was made from a gold foil on a silver base and supposedly attached to a fabric with red, black and white pigments to render a human face; however, it is quite small, measuring only $4.5 \times 4.3 \mathrm{~cm}$. (Tong and Li, 2016,85; Bellezza, 2013). At Chuvthag, another intricately embossed mask of similar size $(5,5 \mathrm{~cm} \times 4.3 \mathrm{~cm})$ was recovered, with the facial traits impressed onto a gold sheet and outlined by red pigments (Insitute of Archaeology, CASS - 2016, 43). Finally, a similar mask was found at the site of Malari in the Uttarakhand Himalaya, Northern India. It is embossed and bears perimetral perforations, but is not painted (Aldenderfer, 2013; Bellezza, 2013; Bhatt et al. 2009).

These masks appear to be part of a larger cultural phenomenon that stretches from Mustang well into Central Asia (Aldenderfer, 2018). Although locally produced, the tradition of their use may well have origins in the northwestern Himalayas and beyond. Masks similar to those found at Samdzong and the western Tibetan cemeteries have been found in Kyrgyzstan at Shamsi 300-400 CE (Kožomberdieva et al., 1998); this mask is reputed to be a part of a widespread tradition of burial masks found in central Eurasian societies at this time (Benkö, 1992; see also van Roon 2014 for a discussion of these masks). Another golden mask has been recovered from the Boma cemetery in Xinjiang (Koch, 2008) and is said to date to 400-500 CE. Although the western Tibetan and NW Indian masks are thought to be earlier than those from Eurasia or Inner Asia, it is possible that their appearance dates to after $250 \mathrm{BCE}$. Given the variability in the crafting of these masks, the differences in their decoration and sizes, it is likely that these masks were adopted into existing local mortuary traditions.

\section{Lead isotope analyses}

Lead isotope analysis was performed on most of the samples available from the site with the exception of sample SMZ1-C2-1, one of the gold/silver masks. The results, shown in Table 4, suggest that, regardless of the composition, the metals are broadly consistent with a single geographic origin. The only exception is found in the copper used for the bead that might belong to a different location as it distinctively separates from the group (Fig. 19). Lead isotopic results require comparable material from the relevant geological areas to investigate a possible origin of the material used for the artefacts. Unfortunately, nothing is available specifically for Mustang or Nepal although a few studies with published data are available for the neighbouring regions and East Asia. We have therefore had to compile data for metal artefacts, slag, rocks and ores, to obtain some broad regional signatures 
(Bhutta and Quareshi, 1997; Brill et al., 1997; Chiaradia et al., 2006; Craddock et al., 2015; Ericson and Shirahata, 1985; Mabuchi et al., 1985; Pavlova and Borisenko, 2009; Pryce et al., 2014; Shah et al., 2010; Srinivasan, 1999; Vishwakarma and Ulabhaje, 1991; Li et al., 2009; Chang and Zhu, 2002). Interestingly, the results (Fig. 20) do not clearly match any specific region among the ones included for comparison. While the copper bead seems closer to Indian material, the rest of the collection is consistent only with artefacts (but not ores) recovered in South-East Asia. However, in the publication from which we obtain these data, Pryce et al. (2014) interpreted Thai artefacts as resulting of trade connections with regions such as India or China, and we concur that a Southeast Asian origin for the objects found in Nepal is unlikely.

Table 4. Results of lead isotopes analyses for a selection of artefacts recovered in Samdzong. Lead isotopes analyses on Samdzong artefacts

\begin{tabular}{lcccc}
\hline \hline Sample Object & $206 \mathrm{~Pb} / 204 \mathrm{~Pb}$ & $207 \mathrm{~Pb} / 204 \mathrm{~Pb}$ & $208 \mathrm{~Pb} / 204 \mathrm{~Pb}$ \\
\hline \hline SMZ1-C4-1 Mask & $17.8422 \pm 0.0008$ & $15.6677 \pm 0.0007$ & $37.9305 \pm 0.0020$
\end{tabular}

SMZ1-C4-2 Bronze Medallion $18.3123 \pm 0.000815 .7376 \pm 0.000738 .5768 \pm 0.0020$

SMZ5-1 Au Mask - Gold front $18.3583 \pm 0.000815 .7108 \pm 0.000738 .4969 \pm 0.0020$

SMZ5-1 Ag Mask - Silver back $18.1421 \pm 0.000815 .6787 \pm 0.000838 .2194 \pm 0.0021$

\begin{tabular}{lll}
\hline \hline SMZ5-2 & Copper bead & $16.7570 \pm 0.000715 .7416 \pm 0.000736 .7048 \pm 0.0018$ \\
\hline \hline SMZ5-3 & Copper cauldron & $18.3825 \pm 0.000815 .7695 \pm 0.000838 .5853 \pm 0.0021$ \\
\hline \hline SMZ5-7 & Brass Rod & $18.3543 \pm 0.000915 .7725 \pm 0.000838 .3867 \pm 0.0020$ \\
\hline \hline SMZ5-8 & Brass strip & $18.3590 \pm 0.000815 .7741 \pm 0.000838 .3990 \pm 0.0020$ \\
\hline \hline SMZ5-11 & Bronze fragment & $18.2629 \pm 0.000715 .7564 \pm 0.000738 .3464 \pm 0.0018$
\end{tabular}



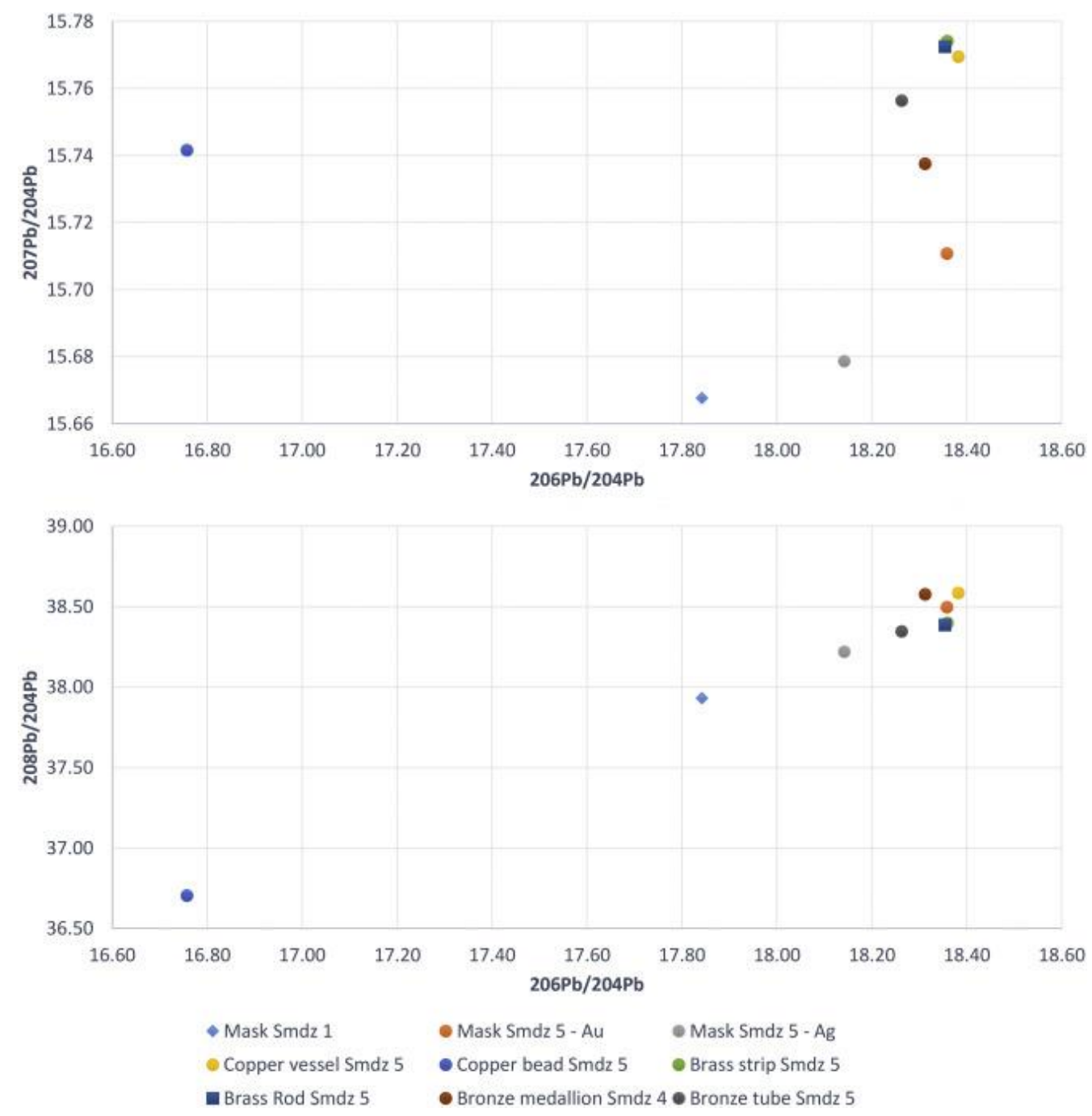

Fig. 19. Mirror plots of the lead isotope ratios for artefacts recovered in Samdzong. 

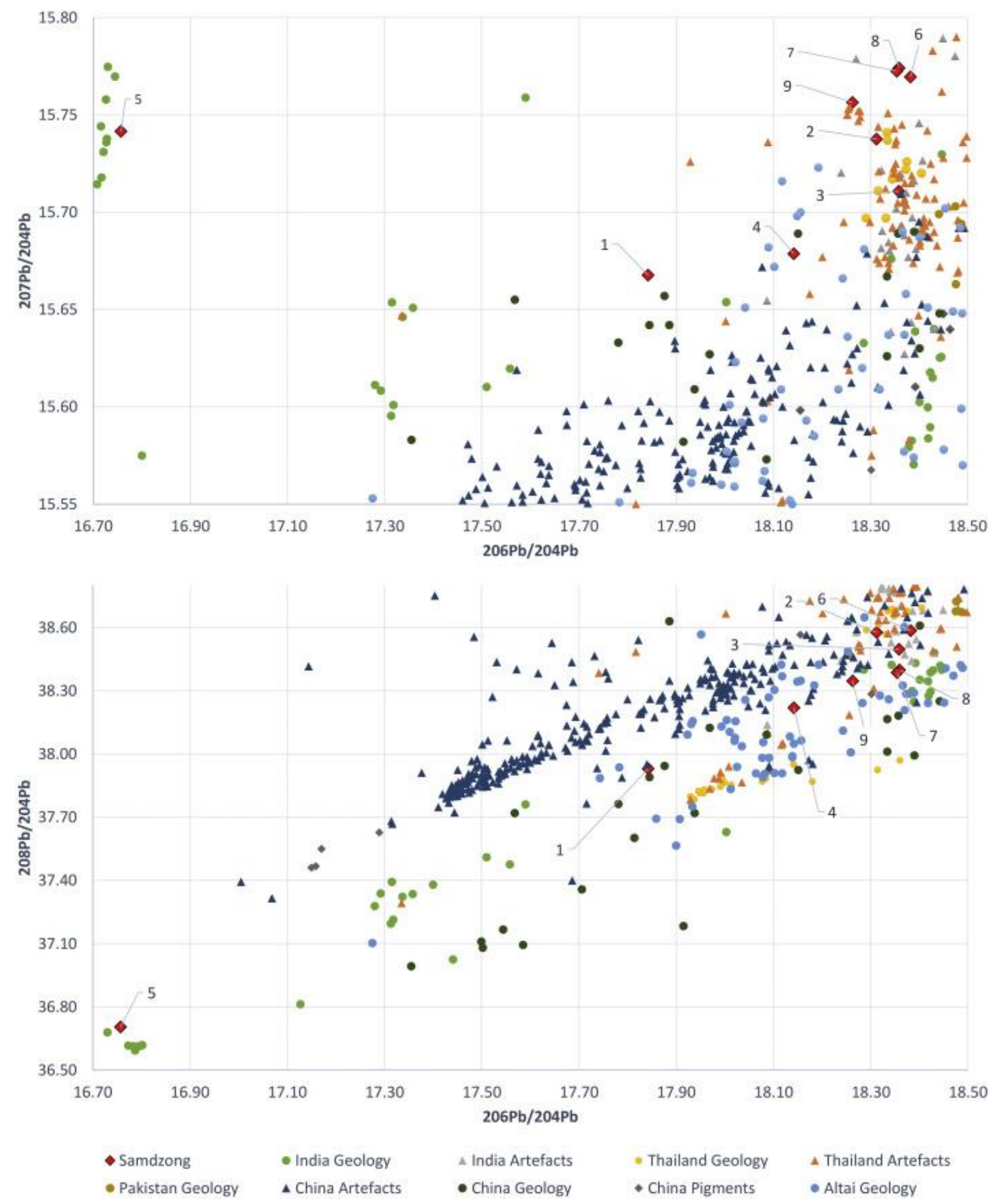

Fig. 20. Mirror plots comparing the lead isotope signature of the Samdzong artefacts to published data from a variety of materials across Asia. Legend for Samdzong: 1) SMZ1-C4-1 2) SMZ1-C4-2 3) SMZ5-1 Au 4) SMZ5-1 Ag 5) SMZ5-2 6) SMZ5-3 7) SMZ5-7 8) SMZ5-8 9) SMZ5-11.

\section{Conclusions}

Notwithstanding the limitations mentioned, the results of the chemical and isotopic analyses would seem consistent with a South Asian origin for the bulk of the metals recovered at Samdzong. This tentative conclusion is supported on stylistic grounds as well. The brass objects, as well as the large copper vessel, all show clear technological affinities to South Asian comparanda. The origin of the bronze objects, especially the medallion, is more complex. Its high tin content signals an ore source in 
India or perhaps southeastern Asia where technological traditions for high-tin bronzes are also found, but stylistically, it is very similar to mirrors and medallions found in Central Asia or possibly in Tibet. Further, the skills required to fabricate an object of this type stand in contrast to the predominantly cold-hammered nature of the rest of the objects, and hence a local manufacture for the medallion seems unlikely. The gold and silver masks offer a different interpretative challenge. Although gold is known from some Nepali sources, there are much larger and better-known gold sources in western Tibet. Although detailed analytical studies of the western Tibetan masks have not been published, it is likely that these masks were locally produced given the relatively low skill level and technological demands required for their fabrication. It is likely that the masks from Samdzong were fabricated locally as well since there is evidence for the recycling of the metals used to make them. This inference is reasonable from a behavioural perspective as well. These masks were likely fabricated at or near the time of death of the person for whom they were made. Moreover, the variability in their design and stylistic details suggests that while the tradition of use of gold masks was widespread through the Himalayas into Central Asia, they were inserted into local burial practices across this region. However, these conclusions are not definitive, because comparable material from Nepal or the Tibetan plateau has either not been discovered or has not been published in sufficient detail (Huo, 2016).

Despite their tentative nature, these results support the inference that the inhabitants of Samdzong participated in an extensive trade network. The Kali Gandahki valley in historical times was on a salt trading route that connected the Tibetan plateau with south Asia (Dhungel, 2002), and some reconstructions of the Silk Route show a spur line that connects Upper Mustang with Lumbini in southern Nepal with a major east-west trade route in northern India (Williams, 2014). We have already noted the presence of Chinese silk in Samdzong 5 (Gleba et al., 2016). By which route the silk made it to Samdzong is not clear, but it could have moved along a route that crossed Tibet and which brought the medallion into the region from Central Asia. An extensive study of the glass beads found in Samdzong 5, which were found on fabric remains associated with the copper beads, indicates source areas from Sassania in the distant West, the Sindh (western Pakistan), the Deccan Plateau, and south India/SE/Asia/Sri Lanka (Aldenderfer and Dussubieux, 2015). Finally, food proteins and grains might have been found in the residue of a bamboo cup found in Samdzong 5 with further analysis still in progress (Christina Warinner, personal communication, February 2018). The metals, then, should be seen as a significant part of this extensive trading network.

\section{Acknowledgements}

This study has been made possible thanks to the help of several people located in various countries and institutions. We would like to thank the SEM lab manager Tom Gregory and lab technician Agnese Benzonelli at UCL Institute of Archaeology for their assistance with the analyses performed at the Institute. We are also grateful to Paul T. Craddock for providing some of his lead isotopes data. Excavations at Samdzong were supported by grants to Aldenderfer (National Geographic Society \#8425-08, National Geographic Society 8810-10 and the National Science Foundation BCS-1528698). The authors also thank the Department of Archaeology, Government of Nepal, for our excavation and export permits. 


\section{References}

Agrawal and Seshadri, 1998

D.P. Agrawal, R. SeshadriThe metallurgical tradition of the Harappans

V. Tripathi (Ed.), Archeometallurgy in India, Sharada, Delhi (1998), pp. 10-17

Aldenderfer, 2013

M. AldenderferVariation in mortuary practice on the early Tibetan plateau and the high Himalayas J. Int. Assoc. Bon Res., 1 (2013), pp. 293-318

Aldenderfer, 2018

M. AldenderferArchaeological evidence and the definition of Zhangzhung

Tsering Tsar (Ed.), Ancient Civilization of the Tibetan Plateau, Minzu University, Bejing (2018), pp. 121144

Aldenderfer and Dussubieux, 2015

M. Aldenderfer, L. DussubieuxRegional connections identified through analysis of glass beads from Samdzong, Upper Mustang, Nepal, AD 500

Presented at the 80th Annual Meeting of the Society for American Archaeology, San Francisco, California, April (2015)

Aldenderfer and Eng, 2016

M. Aldenderfer, J.T. EngDeath and burial among two ancient high-altitude communities of Nepal G.R. Schug, S.R. Walimbe (Eds.), A Companion to South Asia in the Past, John Wiley \& Sons, Inc, Hoboken, NJ (2016), pp. 374-398

Allchin, 1962

F.R. AllchinUpon the antiquity and methods of gold mining in Ancient India

J. Econ. Soc. Hist. Orient, 5 (2) (1962), pp. 195-211

Anfinset, 2000

$\mathrm{N}$. AnfinsetMining and smelting copper in contemporary Nepal. A discussion of its form, function and context

H. Vankilde, D. Olausson (Eds.), Form, Function and Context, Acta Archaeologica Lundensia, Lund. Sweden (2000), pp. 203-212

Artioli and Angelini, 2010

G. Artioli, I. AngeliniScientific Methods and Cultural Heritage: An Introduction to the Application of Materials Science to Archaeometry and Conservation Science

Oxford University Press, Oxford (2010)

Babu, 2003

T.M. BabuAdvent of the Bronze Age in the Indian subcontinent

P.T. Craddock, J. Lang (Eds.), Mining and metal production through the ages, The British Museum Press, London (2003), pp. 231-257

Barnard, 1961

N. BarnardBronze Casting and Bronze Alloys in Ancient China

The Australian National University, Canberra (1961)

Baumer, 2012

C. BaumerThe History of Central Asia: The Age of the Steppe Warriors 
Volume One, I.B. Tauris, London (2012)

Bellezza, 2008

J.V. BellezzaZhang Zhung: Foundations of Civilization in Tibet: A Historical and Ethnoarchaeological Study of the Monuments, Rock Art, Texts, and Oral Tradition of the Ancient Tibetan Upland Verlag der Österreichischen Akademie der Wissrenschaften, Vienna (2008)

Bellezza, 2013

Bellezza, J. V., 2013. Flight of the Khyung [Online]. Available from: http://www.tibetarchaeology.com/november-2013/ [Access 14th of June 2016].

Benkő, 1992

M. BenkőBurial masks of Eurasian mounted nomad peoples in the migration period (1st millennium A.D.)

Acta Orient. Acad. Sci. Hungaricae, 46 (2/3) (1992), pp. 113-131

Bhatt et al., 2008-2009

R.C. Bhatt, K.L. Kavamme, V. Nauti Yak, K.P. Nauti Yal, S. Juyal, S.C. Nauti YalArchaeological and geophysical investigations of high mountain cave burials in Uttarakhand Himalaya, India Indo-Koko-Kenkyu-Studies in South Asian Art and Archaeology, 30 (2008-2009), pp. 1-16

Bhutta and Quareshi, 1997

A.M. Bhutta, I.H. QuareshiLead isotopic character of galenas associated with the lead-zinc barite distribution in the Axial Belt, Balochistan Province, Pakistan, with special reference to the Duddar deposits

N.P. Wyjayananda, P.G. Cooray, P. Mosley (Eds.), Geology in South Asia-II, Geological Survey \& Mines Bureau, Sri Lanka (1997), pp. 301-308

Professional Paper 7

Biswas and Biswas, 1996

A.K. Biswas, S. BiswasMinerals and Metals in Ancient India

D.K. Printworld, New Delhi (1996)

Brill et al., 1997

R.H. Brill, C. Felker-Dennis, H. Shirahata, E.C. JoelLead isotope analyses of some Chinese and Central Asian Pigments

Conservation of Ancient Sites on the Silk Road, The Getty Conservation Institute, Los Angeles (1997), pp. 369-378

Bronson and Charoenwongsa, 1994

B. Bronson, P. CharoenwongsaEyewitness accounts of the early mining and smelting of metals in mainland Southeast Asia

Spafa J., 4 (2) (1994), pp. 4-17

Brown and Dey, 1955

J.G. Brown, A.K. DeyIndia's Mineral Wealth. A Guide to the Occurrence and Economics of the Useful Minerals of India, Pakistan and Burma

(Third edition), Oxford University Press, London (1955)

Cahill, 2009

S.E. CahillThe Lloyd Cotsen Study Collection of Chinese Bronze Mirrors 
Volume I, Cotsen Occasional Press, UCLA Cotsen Institute of Archaeology Press, Los Angeles (2009)

Catalogue

Caley, 1964

E.R. CaleyOrichalcum and Related Ancient Alloys: Origins, Composition and Manufacture With Special Reference to the Coinage of the Roman Empire

The American Numismatic Society, New York (1964)

(Numismatic Notes and Monographs 151)

Chang and Zhu, 2002

$X$. Chang, B. Zhulsotope geochemistry of the Dongchuan copper deposit, Yunnan, SW China: stratigraphic chronology and application of lead isotopes in geochemical exploration

Acta Geochim., 21 (1) (2002), pp. 65-72

Chernyshev et al., 2007

I.V. Chernyshev, A.V. Chugaev, K.N. ShataginHigh-precision Pb isotope analysis by multicollector-ICPmass-spectrometry using 205TI/203TI normalization: optimization and calibration of the method for the studies of $\mathrm{Pb}$ isotope variations

Geochem. Int., 45 (2007), pp. 1065-1076

Chiaradia et al., 2006

M. Chiaradia, D. Konopelko, R. Seltmann, R. CliffLead isotope variations across terrane boundaries of the Tien Shan and Chinese Altay

Mineral. Deposita, 41 (5) (2006), pp. 411-428

Craddock, 1979

P.T. CraddockThe copper alloys of the medieval Islamic world - inheritors of the classical tradition World Archaeol., 11 (1) (1979), pp. 68-79

Craddock, 1981

P.T. CraddockThe copper alloys of Tibet and their background

W.A. Oddy, W. Zwalf (Eds.), Aspects of Tibetan Metallurgy, British Museum, London (1981), pp. 1-31

British Museum Occasional Paper 15

Craddock et al., 1998

Craddock, P.T., La Niece, S. C. and Hook, D. R., 1998. Brass in the medieval Islamic world. In: P. T. Craddock (ed.), 2000 Years of Zinc and Brass. (Revised edition). London: British Museum. British Museum Occasional Paper 50, 73-102.

Craddock et al., 2013

P.T. Craddock, C. Cartwright, K. Eckstein, I. Freestone, L. Gurjar, D. Hook, A. Middleton, L. WilliesSimple sophistication: Mauryan silver production in north West India

Br. Museum Tech. Bull., 7 (2013), pp. 79-93

Craddock et al., 2015

Craddock, P.T., Cribb J., Gale, N., and Gurjar, L., 2015. Sources of zinc in early India: The evidence of numismatics, trade and lead isotope analysis. In: Srinivasan, S.M.N., Giumlia-Mair, A. and Ranganathan, S. (Eds.), Metals and Civilizations: Proceedings of the Seventh International Conference on the Beginnings of the Use of Metals and Alloys (BUMA VII). Bangalore: National Institute of Advanced Studies, 174-184. 
Dhungel, 2002

R.K. DhungelThe Kingdom of Lo (Mustang): A Historical Study

Lusha Press, Kathmandu (2002)

Environment and Development Division (EDD), 1993

Environment and Development Division (EDD)Atlas of Mineral Resources of the ESCAP Region Geology and Mineral Resources of Nepal Vol. 9

ESCAP, Bangkok (1993)

Ericson and Shirahata, 1985

J.E. Ericson, H. ShirahataLead isotope analysis of ancient copper and base metal ore deposits in Western India

P.A. England, L. van Zelst (Eds.), Application of Science in Examination of Works of Art, Research Laboratory, Museum of Fine Arts, Boston (1985), pp. 207-212

Furger, 2017

A. FurgerThe Gilded Buddha: The Traditional Art of Newari Metal Casters in Nepal

Librum Publishers and Editors, Basel (2017)

Gleba et al., 2016

M. Gleba, I. Vanden Berghe, M. AldenderferTextile technology in Nepal in the 5th-7th centuries CE: the case of Samdzong

STAR, 2 (1) (2016), pp. 25-35

Horlyck, 2011

C. HorlyckMirrors in early Korea

L. von Falkenhausen (Ed.), The Lloyd Cotsen Study Collection of Chinese Bronze Mirrors. Volume II: Studies, Cotsen Occasional Press, UCLA Cotsen Institute of Archaeology Press, Los Angeles (2011), pp. 120-129

Huo, 2016

W. HuoOn the early metal objects and early metal age in Tibet

Chinese Archaeol., 16 (2016), pp. 91-96

Insitute of Archaeology, CASS and Cultural Relics Conservation Institute of Tibet Autonomous Region, 2014

Insitute of Archaeology, CASS and Cultural Relics Conservation Institute of Tibet Autonomous RegionThe excavation of the Gurugyam cemetery in Gar County, Ngari prefecture, Tibet Autonomous Region in 2012

Kaogu Xuebao, 4 (2014), pp. 563-587 (in Chinese)

Institute of Archaeology, CASS and Cultural Relics Conservation Institute of Tibet Autonomous Region, 2016

Institute of Archaeology, CASS and Cultural Relics Conservation Institute of Tibet Autonomous RegionThe Gurugyam and Chuvthag Cemeteries in Ngari Prefecture,Tibet

Kaogu Xuebao, 16 (2016), pp. 27-48

Koch, 2008

A. KochBoma - "A Horse Nomad - Hunnic Assemblage in Northwestern China" 
Historisches Museum der Pfalz, Speyer (Ed.), The Huns between Asia and Europe. Current Research in Archaeology and Culture of the Huns, Beiträge zur Ur- und Frühgeschichte Mitteleuropas, Beier \& Beran, Langenweissbach (2008), pp. 57-71

Kožomberdieva et al., 1998

E.I. Kožomberdieva, I.V. Kožomberdiev, P.N. KožemjakovEin Katakombengrab aus der Schlucht Šamsi Eurasia Antiqua, 4 (1998), pp. 451-471

Lai, 2011

G. LaiA Liao-dynasty Buddhist Votive mirror in the Cotsen collection

L. von Falkenhausen (Ed.), The Lloyd Cotsen Study Collection of Chinese Bronze Mirrors. Volume II: Studies, Cotsen Occasional Press, UCLA Cotsen Institute of Archaeology Press, Los Angeles (2011), pp. 184-197

Li et al., 2009

W. Li, D. Jun, Y. Gao, Z. Guo, Z. Zhang, Z. SongGeology, geochemistry and minerogenesis of the Shijuligou zinc-copper deposit in Gansu, China

Acta Geol. Sin. (English Edition), 83 (6) (2009), pp. 1052-1063

Lo Bue, 1981

E. Lo BueStatuary metals in Tibet and the Himalayas: History, tradition and modern use W.A. Oddy, W. Zwalf (Eds.), Aspects of Tibetan Metallurgy, British Museum, London (1981), pp. 33-67 British Museum Occasional Paper 15

Mabuchi et al., 1985

H. Mabuchi, Y. Hirao, M. NishidaLead isotope approach to the understanding of Early Japanese Bronze Culture

Archaeometry, 27 (2) (1985), pp. 131-159

Marshall, 1951

J. MarshallTaxila: An Illustrated Account of Archaeological Excavations Carried Out at Taxila under the Orders of the Government of India between the Years 1913 and 1934

Cambridge University Press, Cambridge, Eng (1951)

Martynov, 1991

A.I. MartynovThe Ancient Art of Northern Asia

Translated and edited from Russian by D. B. Shimkin and E. Shimkin

University of Illinois Press, Urbana (1991)

Meeks, 1986

N.D. MeeksTin-rich surfaces on bronze - some experimental and archaeological considerations

Archaeometry, 28 (2) (1986), pp. 133-162

Mei et al., 2015

J. Mei, P. Wang, K. Chen, L. Wang, Y. Wang, Y. LiuArchaeometallurgical studies in China: some recent developments and challenging issues

J. Archaeol. Sci., 56 (2015), pp. 221-232

Murillo-Barroso et al., 2010

M. Murillo-Barroso, T.O. Pryce, B. Bellina, M. Martinón-TorresKhao Sam Kaeo - an archaeometallurgical crossroads for trans-Asiatic technological styles 
Oddy, 1991

W.A. OddyGilding: an outline of the technological history of the plating of gold on to silver or copper in the old world

Endeavour, 15 (1) (1991), pp. 29-33

Oddy et al., 1981

W.A. Oddy, S. La Niece, J.E. Curtis, N.D. MeeksDiffusion bonding as a method of gilding in antiquity MASCA J., 1 (8) (1981), pp. 239-241

Pavlova and Borisenko, 2009

Pavlova, BorisenkoThe age of $\mathrm{Ag}-\mathrm{Sb}$ deposits of Central Asia and their correlation with other types of ore systems and magmatism

Ore Geol. Rev., 35 (2) (2009), pp. 164-185

Pryce et al., 2014

T.O. Pryce, S. Baron, B. Bellina, P.S. Bellwood, N. Chang, P. Chattopadhyay, et al.More questions than answers: the Southeast Asian Lead Isotope Project 2009-2012

J. Archaeol. Sci., 42 (2014), pp. 273-294

Ranganathan et al., 2010

S. Ranganathan, S. Srinivasan, I. GloverIndian High Tin Bronzes: A continuing tradition from ancient to modern times

International Symposium of Asian High-Tin Bronzes, Production Technology Regional Characteristics, Japan Society for Promotion of Science, Tokyo (2010), pp. 201-209

Rao, 1985

S.R. RaoLothal. A Harappan Port Town. VOL. II

Archaeological Survey of India, New Delhi (1985)

Reedy, 1997

C.L. ReedyHimalayan Bronzes - Technology, Style and Choices

University of Delaware press, Newark (1997)

Rehren et al., 1996

T. Rehren, K. Hess, G. PhilipAuriferous silver in Western Asia: ore or alloy?

Hist. Metall., 30 (10) (1996), pp. 1-10

Samans, 1963

C.H. SamansMetallic Materials in Engineering

Macmillan Company, New York (1963)

Scott, 1991

D.A. ScottMetallography and Microstructure of Ancient and Historic Metals

Marina del Rey, Getty Conservation Institute, CA (1991)

Shah et al., 2010

M. Shah, T. Khan, A. KhanLead isotope signatures of $\mathrm{Pb}-\mathrm{Zn}$ sulfide mineralization in the ReshianLamnian area of Azad Jammu and Kashmir, Pakistan

Acta Geochem., 29 (1) (2010), pp. 65-74 
Sharma, 2004

D.P. SharmaEarly Buddisth metal images of South and SoutheastAsia

A. Pande, P.P. Dhar (Eds.), Cultural Interface of India with Asia: Religion, Art and Architecture, D.K. Printworld, New Delhi (2004), pp. 248-295

Simons et al., 1994

A. Simons, W. Schön, S.S. ShresthaThe prehistoric settlement of Mustang: first results of the 1993 archaeological investigations in cave systems and connected ruined sites

Ancient Nepal, 137 (1994), pp. 93-129

Slusser and Vajracharya, 1975

M.S. Slusser, G. VajracharyaOn the antiquity of Nepalese metalcraft

Arch. Asian Art, 29 (1975), pp. 80-95

Srinivasan, 1994

S. SrinivasanHigh-tin bronze bowl making in Kerala, South India, and its archaeological implications

A. Parpola, P. Koskikallio (Eds.), South Asian Archaeology, 1993: Proceedings of the twelfth International Conference of the European Association of South Asian Archaeologists held in Helsinki University, 5-9 July 1993 (Suomalaisen Tiedeakatemian toimituksia. Sarja B; nide 271), Suomalainen Tiedeakatemia, Helsinki (1994), pp. 695-705

Srinivasan, 1997

S. SrinivasanPresent and past of southern Indian crafts for making mirrors, lamps, bells, vessels, cymbals and gongs: links with prehistoric high tin Bronzes from Mohenjodaro, Taxila, south Indian megaliths, and later finds

South Asian Stud., 13 (1) (1997), pp. 209-225

Srinivasan, 1998

S. SrinivasanThe use of tin and bronze in prehistoric southern Indian metallurgy

J. Metals, 50 (7) (1998), pp. 44-48

Srinivasan, 1999

S. SrinivasanLead isotope and trace element analysis in the study of over a hundred south Indian metal icons

Archaeometry, 41 (1) (1999), pp. 91-116

Srinivasan, 2008

S. SrinivasanMirrors: metal mirrors from India

$\mathrm{H}$. Selin (Ed.), Encyclopaedia of the History of Science, Technology, and Medicine in Non-Western

Cultures (2nd ed., Springer reference. Y), Springer, Berlin; New York (2008), pp. 1699-1704

Srinivasan, 2010

S. SrinivasanMegalithic high-tin bronzes and India's living prehistory

B. Bellina, T.O. Pryce, E. Bacus, J.W. Christie (Eds.), 50 years of Southeast Asian Archaeology: Essays in Honour of lan Glover, River Books, Bangkok (2010), pp. 239-271

Srinivasan, 2013

S. SrinivasanMegalithic and continuing peninsular high-tin binary Bronzes: possible roots in Harappan binary bronze usage?

Trans. Indian Instit. Metals, 66 (5) (2013), pp. 731-737 
Stos-Gale and Gale, 2009

Z. Stos-Gale, A. GaleMetal provenancing using isotopes and the Oxford archaeological lead isotope database (OXALID)

Archaeol. Anthropol. Sci., 1 (3) (2009), pp. 195-213

Tong and Li, 2016

T. Tong, L. LiThe Himalayan gold masks from the Eurasian perspective

Chinese Archaeol., 16 (2016), pp. 85-90

Vishwakarma and Ulabhaje, 1991

R.K. Vishwakarma, A.V. UlabhajeSargipali galenas: unusual lead-isotope data from eastern India Mineral. Deposita, 26 (1) (1991), pp. 26-29

Walder et al., 1993

A.J. Walder, I. Platzner, P.A. Freedmanlsotope ratio measurement of lead, neodymium and neodymium-samarium mixtures, hafnium and hafnium-lutetium mixtures with a double focusing multiple collector inductively coupled plasma mass spectrometer

J. Anal. At. Spectrom., 8 (1993), pp. 19-23

Williams, 2014

T. WilliamsThe Silk Roads: An ICOMOS Thematic Study

International Council of Monuments and Sites. Charenton-le-Pont, France (2014)

Wong, 2001

Y. WongBronze mirror art of the Han Dynasty

Chinese Bronzes (Ed.), Selected Articles from Orientations 1983-2000, Hong Kong, Orientations Magazine Ltd (2001), pp. 56-67 